\title{
Cellulose, Nanocellulose, and Antimicrobial Materials for the Manufacture of Disposable Face Masks: A Review
}

\author{
Rosilei A. Garcia, ${ }^{\mathrm{a}, *}$ Tatjana Stevanovic, ${ }^{\mathrm{a}}$ Joëlle Berthier, ${ }^{\mathrm{b}}$ Guy Njamen, ${ }^{\mathrm{c}}$ Balázs Tolnai, \\ and Alexis Achim ${ }^{a}$
}

\begin{abstract}
Cellulose is among the most promising renewable and biodegradable materials that can help meet the challenge of replacing synthetic fibers currently used in disposable N95 respirators and medical face masks. Cellulose also offers key functionalities that can be valued in filtration applications using approaches such as nanofiltration, membrane technologies, and composite structures, either through the use of nanocellulose or the design of functional composite filters. This paper presents a review of the structures and compositions of N95 respirators and medical face masks, their properties, and regulatory standards. It also reviews the use of cellulose and nanocellulose materials for mask manufacturing, along with other (nano)materials and composites that can add antimicrobial functionality to the material. A discussion of the most recent technologies providing antimicrobial properties to protective masks (by the introduction of natural bioactive compounds, metal-containing materials, metal-organic frameworks, inorganic salts, synthetic polymers, and carbon-based 2D nanomaterials) is presented. This review demonstrates that cellulose can be a solution for producing biodegradable masks from local resources in response to the high demand due to the COVID-19 pandemic and for producing antimicrobial filters to provide greater protection to the wearer and the environment, reducing crosscontamination risks during use and handling, and environmental concerns regarding disposal after use.
\end{abstract}

Keywords: Antimicrobial properties; Cellulosic biomaterials; Cellulose filaments; COVID-19; Fibrillated cellulose; Filter media; Medical face masks; $N 95$ respirators; Personal protective equipment; SARS-CoV-2

Contact information: a: Département des sciences du bois et de la forêt, Centre de recherche sur les matériaux renouvelables, Université Laval, Pavillon Gene-H.-Kruger, 2425 rue de la Terrasse, Québec, QC G1V 0A6, Canada; b: Kruger Biomaterials Inc., 3285 Chemin Bedford, Montréal, QC H3S 1 G5 Canada; c: Kruger Inc., 3285 Chemin Bedford, Montréal, QC H3S 1 G5 Canada;

* Corresponding author: Rosilei.Aparecida-Garcia@sbf.ulaval.ca

\section{INTRODUCTION}

The outbreak of coronavirus disease 2019 (COVID-19) and the associated collapse of the global supply chain have resulted in a severe global shortage of personal protective equipment (PPE) - especially N95 respirators and medical face masks - for healthcare personnel, thereby stimulating the search for local supply sources and innovative solutions. Additionally, the use of non-medical masks by the entire population has been imposed by several jurisdictions worldwide in an effort to mitigate the spread of severe acute respiratory syndrome coronavirus 2 (SARS-CoV-2), which causes COVID-19, and has also led to an increasing demand for masks. Currently, protective face masks are generally made from petroleum-based synthetic fibers, although the use of biodegradable materials 
with a lower carbon footprint is preferable, provided the protection performance is maintained. The forestry sector, particularly the pulp and paper industry, plays an important role in the context of the crisis caused by the pandemic, as it can supply a wide variety of cellulose-based products for healthcare personnel and the general public. However, few pulp and paper companies in North America produce medical-grade pulp for PPE. For instance, Canada has a single mill producing medical-grade pulp that can be used in the composition of N95 respirators and other PPE by United States manufacturers. This mill has been operating at full capacity since the appearance of COVID-19 (Business Examiner 2020).

For several reasons, cellulose is one of the most promising alternative materials that can be used to partially or entirely replace synthetic fibers traditionally used as filter media in the manufacture of disposable N95 respirators and medical and non-medical face masks. These reasons include its biodegradability, renewability, low cost, abundance, ease of processing, adjustable aspect ratio, strong mechanical properties, and low density, compared to other materials (Tavakolian et al. 2020). Both N95 respirators and medical face masks require a combination of high filtration capacity and good performance against the penetration of pathogens. The latter requires, among other characteristics, water repellency, as liquid droplets may contain viral agents (Shimasaki et al. 2020), and also bioactive properties including mainly an antimicrobial action (Ristić et al. 2011). Face masks should also allow for a low pressure drop (i.e., high air permeability) to facilitate breathing (Osman 2020), while being comfortable, soft, light, and non-allergenic to the wearer's skin (Zanoaga and Tanasa 2014; Qin 2016), all in accordance to regulatory standards (42 CFR Part 84 1995; NIOSH 2014; ASTM F2100-19e1 2019; NPPTL 2020). Both N95 and medical face masks made of synthetic fibers have a high level of filtration of greater than $95 \%$; however, few masks available on the market have antiviral activities, meaning that they filter microorganisms but do not deactivate them. This in turn increases the risk of cross-contamination (from the contaminated mask to the wearer or the environment) during use and handling and raises further environmental concerns about their disposal after use (Zhou et al. 2020). Cellulose fibers provide desirable properties to filter media (e.g., bulk, permeability, and mechanical strength) and can act as a support structure for the thin and weaker filter media such as meltblown and electrospun matrices (Hutten 2016). Additionally, surface modification of cellulose fibers is considered an excellent option for adding antimicrobial functionality to medical and healthcare products. Although it does not exhibit intrinsic biocidal activities like some biopolymers, e.g., chitosan, the cellulose surface is reactive, so it can be chemically modified to graft certain functionalities into its structure (Tavakolian et al. 2020). Several technologies have been developed to introduce bioactive compounds, including plant-based products (CatelFerreira et al. 2015; Gargoubi et al. 2020), animal-derived chitosan and chitosan derivates (Ling et al. 2013; Ahmad et al. 2016), metal and metal compounds (Emam 2019), metalorganic frameworks (MOFs) (an innovative material derived from metal salts) (Nie et al. 2020a), inorganic salts, synthetic polymers (Tavakolian et al. 2020), two-dimensional (2D) nanomaterials such as graphene (Huang et al. 2020), and composite and nanocomposite structures thereof among others, which provide antimicrobial (antibacterial, antifungal, and/or antiviral) properties to cellulose fibers. These antimicrobial materials can be added either during papermaking or as post-treatment coatings to provide effective protection. Furthermore, when cellulose fibers are disintegrated into nanostructures, e.g., nanofibrillated materials, many filter properties and characteristics such as filtration efficiency (Sim and Youn 2016) and surface functionalization are enhanced due to their 
high specific surface. Additionally, cellulose may be combined with other materials, such as polyester fibers, forming composite structures to meet the requirements for filter media (Pan et al. 2019). However, cellulose fibers are inherently hydrophilic, so they tend to absorb water, which softens and weakens the filter structure, reduces its useful life, and inhibits filtration performance due to fiber swelling (Mukhopadhyay 2014). This characteristic of the material increases the risk of contamination during use, as viruses can penetrate through a humid mask (Zhou et al. 2020), while also providing favorable conditions for the proliferation of fungi and bacteria. Therefore, treatments providing antimicrobial and hydrophobic properties must be applied to cellulose-based masks. In short, the use of cellulose fibers and nanocellulose products from wood pulp offers numerous advantages for N95 respirators and medical face masks, yet it also raises some key technical challenges that must be overcome to meet the requirements for good filter performance.

This paper presents a review of the potential applications of cellulose and nanocellulose materials in the development of biodegradable products to replace the petroleum-based synthetic fibers usually used in the manufacture of disposable N95 respirators and medical face masks. It offers 1) an overview of the structures and compositions of disposable protective face masks, their properties, and standard requirements and particularities of the filter media; 2) descriptions of the cellulose and nanocellulose materials that could be used in the manufacturing of mask filters; and 3) a suite of antimicrobial technologies that could be used for cellulose functionalization and that remain potentially safe for use in face masks. The study is partly a result of a joint effort of researchers and industrial partners of the pulp and paper sector to find innovative solutions for bioproducts obtained from locally and sustainably sourced fiber, which will hopefully contribute to limiting the spread of SARS-CoV-2.

\section{DISPOSABLE FACE MASKS}

\section{N95 Respirators}

The National Institute for Occupational Safety and Health (NIOSH) approves particulate filtering facepiece (FFP) respirators according to nine filter classes certified under 42 CFR Part 84 (1995): N95, N99, N100, R95, R99, R100, P95, P99, and P100. The $\mathrm{N}, \mathrm{R}$, and $\mathrm{P}$ designations refer, respectively, to respirators that are non-resistant, resistant, and proof to degradation by oily aerosols. The protection levels of classes 95, 99, and 100 correspond to filtration efficiencies of airborne particles of at least $95 \%, 99 \%$, and $99.97 \%$, respectively. The N95 is therefore a particulate FFP respirator that is non-resistant to oily aerosols and that filters at least $95 \%$ of airborne particles greater than $0.3 \mu \mathrm{m}$, which is considered the most penetrating particle size (MPPS). These respirators are classified as protective devices or PPE and are designed to protect the wearer against the inhalation of hazardous airborne particles, including viruses and bacteria. There are two NIOSHapproved N95 FFP types: standard N95 respirators and surgical N95 respirators, which are also referred to as medical/healthcare respirators and cleared by the US Food and Drug Administration (FDA) (NIOSH 2014; NPPTL 2020). North America follows NIOSH specifications for N95 respirators; however, equivalent FFP respirators from Europe (FFP2), China (KN95), and other countries are commercially available in a variety of shapes and sizes. 
The N95 respirators have a multilayer composite structure with a central filtering layer displaying electret properties, giving an electrostatic charge to a nonwoven fibrous mat often composed of synthetic fibers. They are generally composed of four layers: two layers (outer and inner) of spunbonded polypropylene of low density $\left(20 \mathrm{~g} / \mathrm{m}^{2}\right.$ to $50 \mathrm{~g} / \mathrm{m}^{2}$ basis weight); a thick, stiff, and dense nonwoven layer (approximately $250 \mathrm{~g} / \mathrm{m}^{2}$ basis weight) that gives support to the meltblown layer and that can be molded to give the shape of the mask; and a meltblown layer with electrostatic properties (Henneberry 2020). The electrostatic charge of the filter media is generally obtained by corona discharge, triboelectrification, or electrostatic spinning. Electret treatments provide many advantages to filter media without increasing structural mass or density (Zhao et al. 2020). These advantages include high initial and sustained efficiency during the filter lifecycle, increased submicron particle capture efficiency, filtration efficiency unaffected by relative humidity and long-term storage at high temperatures $\left(54.5{ }^{\circ} \mathrm{C}\right)$, and lower airflow resistance (Mukhopadhyay 2014). The N95 respirator's performance depends on the filtration efficiency as well as on face seal leakage, as respirators must fit tightly to the face of the wearer to create a seal (He et al. 2013).

Filtration performance of N95 respirators is evaluated according to 42 CFR Part 84 (1995) and NIOSH standards by polydisperse sodium chloride $(\mathrm{NaCl})$ aerosol testing with an aerosol concentration not exceeding $200 \mathrm{mg} / \mathrm{m}^{3}$ (typical $\mathrm{NaCl}$ concentrations range from $12 \mathrm{mg} / \mathrm{m}^{3}$ to $20 \mathrm{mg} / \mathrm{m}^{3}$ ) at an 85-L/min flow rate using a TSI 8130 automated filter tester (TSI Incorporated, Shoreview, MN, USA) (Rengasamy et al. 2011, 2013), which is a photometric detection method that uses a forward light scattering photometer to measure the flux of light scattering from particles (Rengasamy et al. 2011). This method determines the penetration or filter efficiency and pressure drop in filter media, filter cartridges, and respiratory masks. The $\mathrm{NaCl}$ aerosol must have a particle size distribution with a count median diameter (CMD) of $0.075 \mu \mathrm{m} \pm 0.020 \mu \mathrm{m}$ (size distribution can be determined using differential mobility analyzers) and a standard geometric deviation (GSD) of less than 1.86. Additionally, the $\mathrm{NaCl}$ aerosol must be at $25^{\circ} \mathrm{C} \pm 5{ }^{\circ} \mathrm{C}$ and $30 \% \pm 10 \%$ relative humidity and neutralized to the Boltzmann equilibrium state (the remaining charged particles must have a bell-shaped distribution curve with the center at zero). The $42 \mathrm{CFR}$ Part 84 (1995) standard requires pre-conditioning of the N95 respirators before the test (at $85 \% \pm 5 \%$ relative humidity and $38{ }^{\circ} \mathrm{C} \pm 2.5{ }^{\circ} \mathrm{C}$ for $25 \mathrm{~h} \pm 1 \mathrm{~h}$ ) because some types of electrostatic filter media can degrade after exposure to high humidity. The filtration efficiency is the percentage of $\mathrm{NaCl}$ particles filtered by the material, while the pressure drop corresponds to the air resistance across the filter material (Zhao et al. 2020). The maximum penetration must not exceed $5 \%$ for class 95 respirator approval.

Other filtration test methods have also been studied. A comparison between the photometric method and another polydisperse $\mathrm{NaCl}$ aerosol penetration method using an ultrafine condensation particle counter (UCPC) to measure the filtration performance of N95 respirators was presented by Rengasamy et al. (2011). The authors showed that aerosol penetrations measured by the UCPC were 2 times to 6 times greater than the levels measured by the photometric method, suggesting the need for the development of a more challenging aerosol testing method for $\mathrm{N} 95$ respirator certification. In addition to the $\mathrm{NaCl}$ aerosol test, N95 respirators must meet other specifications according to 42 CFR Part 84 (1995) and NIOSH standards, such as inhalation and exhalation resistance to airflow ( $\leq$ $343 \mathrm{~Pa}$ and $\leq 245 \mathrm{~Pa}$, respectively) for both N95 types, synthetic blood penetration (ASTM F1862/F1862M-17 2017) and biological filtration efficiency for the surgical N95 type, and exhalation valve leakage (leak rate $30 \mathrm{~mL} / \mathrm{min})$ and force applied $(-245 \mathrm{~Pa})$ for the standard 
N95 type. Other tests can also be performed, such as surface wetting resistance, microorganism index (bioburden) (Davison 2012), $\mathrm{CO}_{2}$ clearance, and total inward leakage (TIL), which quantifies the respirator's ability to fit individual facial dimensions to ensure that the respirator fits properly (not a requirement for respirator approval testing) (He et al. 2013, 2014; Ramirez 2015).

\section{Medical Face Masks}

Medical face masks, also known as surgical masks or procedure masks, are usually composed of three layers of a spunbonded-meltblown-spunbonded (SMS) nonwoven fabric, where the meltblown middle layer provides higher filtration performance compared to the spunbonded layers (Ghosh 2014; Mukhopadhyay 2014). The outer spunbonded layer is typically blue and hydrophobic to prevent liquid droplets containing viral or other hazardous agents from reaching the wearer (Shimasaki et al. 2020), acting as a prefilter layer for the meltblown middle layer that provides the final filtration (Mukhopadhyay 2014). The inner spunbonded layer is soft, for the wearer's comfort, and absorbent, to absorb the fluids generated by breathing, coughing, and sneezing, and it usually has no filtration function. The spunbonded layers are generally made of polypropylene, polyester (polyethylene terephthalate, PET), or other thermoplastic fibers (Henneberry 2020). Cellulose fibers such as cotton or rayon fibers, which are made from regenerated cellulose from wood or agricultural residues, and mixes of cellulose/polyester and cellulose/ polyolefin fibers can also be used in the outer and inner layers (Davison 2012; Ciuffreda et al. 2020; Medline 2020). Spunbonding is a well-known continuous nonwoven process in the field of textiles. It is fast and inexpensive and combines spinning, sheet formation, and bonding: Fibers are spun, dispersed by deflectors or air streams to form a web, and finally bonded by hydroentangling, needle punching, or thermal or chemical methods (Lim 2010).

The meltblown filter of the middle layer is composed typically of polypropylene; however, other synthetic fibers can be used, such as poly(butylene terephthalate), a type of polyester, and poly(tetrafluoroethylene) (PTFE), a thermoplastic polymer with inherently hydrophobic properties used to form a porous membrane structure (Solvay 2020). The pore diameter in PTFE stretched films ranges from $0.1 \mu \mathrm{m}$ to $10 \mu \mathrm{m}$, providing high filtration efficiency, lightness, high air permeability (breathability), and long service life; however, they are expensive and cannot completely replace traditional masks (Hendrikx 2019). The melt blowing process is a conventional method for producing micro- and nanofibers from thermoplastic polymers. In the process, a polymer melt is extruded through small nozzles surrounded by high-velocity hot air to produce fibers that are randomly deposited to form a nonwoven web (Hiremath and Bhat 2015). A combination of SMS technologies, known as a multi-denier process, is also employed to form a composite structure and reach the requirements of protective textiles (Lim 2010). Spunbonded fibers are coarser, have higher tensile strength, and have a smaller pressure drop than meltblown fibers (Mao 2016). The polypropylene microfibers of the meltblown layers have diameters of approximately $1 \mu \mathrm{m}$ to $10 \mu \mathrm{m}$ and a fabric thickness of $100 \mu \mathrm{m}$ to $1000 \mu \mathrm{m}$, which provides high porosity and a limited capacity to filter fine particles (Zhao et al. 2020). For this reason, other filtration technologies are employed to improve filter performance. Unlike N95 respirators, which are electret-treated to improve filtration efficiency against small aerosols, the meltblown layer of medical face masks has no electret properties. The filtration of particles is only mechanical and therefore less efficient than in N95 respirators. Medical face masks are hence designed mainly to prevent the projection of droplets expelled by the wearer into the 
environment, e.g., to prevent surgical infections and to protect others from droplets originating from sick people. Consequently, they offer low protection for the wearer against the inhalation of fine airborne particles.

Prather et al. (2020) offer a helpful explanation to distinguish between aerosols and droplets: Aerosols are smaller than $100 \mu \mathrm{m}$, remain suspended in the air for long periods (ranging from several seconds to hours), and can be inhaled after traveling more than $2 \mathrm{~m}$ and accumulating in poorly ventilated indoor air. In contrast, droplets are larger than 100 $\mu \mathrm{m}$ and fall to the ground in seconds, usually within a distance of $2 \mathrm{~m}$ from the source. Transmission of SARS-CoV-2 occurs by both aerosols and droplets (Prather et al. 2020). Although the filtering efficiency of medical face masks is generally tested with nonbiological particles, a recent study has confirmed their efficiency in preventing transmission of human coronaviruses and influenza viruses from symptomatic individuals, suggesting that their use could also help control COVID-19 transmission (Leung et al. 2020). The study showed that medical face masks significantly reduce the environmental emission of the influenza virus in coarse aerosols (particles $>5 \mu \mathrm{m}$ ) and coronavirus in fine-particle aerosols $(\leq 5 \mu \mathrm{m})$, with a trend to reduce the coronavirus emission in respiratory coarse aerosols. Medical face masks offer more comfort and greater breathability than N95 respirators during use.

Other filtration mechanisms including antiviral technology and nanotechnology have been developed to improve the performances of N95 respirators and medical face masks. The BioFriend ${ }^{\mathrm{TM}}$ BioMask $^{\mathrm{TM}}$ provides FDA-cleared disposable N95 surgical respirators and medical face masks with antiviral properties. These masks are composed of four layers, with two active layers designed to inactivate viruses through different mechanisms of action. The outer active (first) layer is composed of spunbonded polypropylene treated with a hydrophilic plastic coating that absorbs infectious droplets and inactivates viruses by exposure to citric acid derivates. The inner active (second) layer is composed of cellulose (rayon) and polyester fibers treated with positively charged copper and zinc ions. These active layers inactivate different subtypes of influenza A and $\mathrm{B}$ viruses, paramyxovirus (measles), and SARS-CoV-1, which was responsible for the severe acute respiratory syndrome (SARS) outbreak in 2003. The third layer is composed of meltblown polypropylene filter media, while the inner (fourth) layer is composed of spunbonded polypropylene. The antiviral N95 respirators and medical face masks have the same structure, except for the meltblown material used in the third layer of the N95 respirator, which has increased filtration efficiency to meet the required specifications (Davison 2012). The same antiviral technology is used on the Innonix RespoKare ${ }^{\circledR}$ surgical masks, which inactivate many pathogens, including coronaviruses, but they had not yet been proven efficient for SARS-CoV-2 (RespoKare 2017). Additionally, the Inovenso company has developed a new generation of nanofiber face masks, named Inofilter ${ }^{\circledR}$ 95/99, with a three-layer structure made of PET spunbonded nonwoven fabric in the outer and inner layers $\left(35 \mathrm{~g} / \mathrm{m}^{2}\right.$ basis weight for each layer) and a nanofiber membrane in the middle layer $\left(0.6 \mathrm{~g} / \mathrm{m}^{2}\right.$ to $0.8 \mathrm{~g} / \mathrm{m}^{2}$ basis weight $)$ replacing the meltblown middle layer conventionally used in face masks. The nanofiber membrane is made of a thermoplastic fluoropolymer (polyvinylidene fluoride, PVDF) using a patented hybrid electrospinning technology. The PVDF nanofiber membrane has fibers with a diameter of approximately $224 \mathrm{~nm}$ and is designed to provide a high mechanical filtration efficiency of $96 \%$ to $99 \%$, inhalation protection, and low pressure drop. Another similar version of the nanofiber filter, the Inofilter $\mathrm{V}^{\circledR}$, provides additional properties such as $99.9 \%$ viral filtration efficiency, 
inhalation and exhalation protection, and resistance to liquids like blood and oil (Inovenso Technology 2018).

Medical face masks must meet five specifications for filtering according to the ASTM F2100-19e1 (2019) standard: 1) bacterial filtration efficiency (BFE), 2) submicron particulate filtration efficiency (PFE), 3) differential pressure $(\Delta P)$, 4) resistance to penetration by synthetic blood, and 5) flammability. Medical face masks are classified according to three levels of protection: Level 1 (low), Level 2 (moderate), and Level 3 (high), with differing specifications. The BFE tests measure the percent efficiency of the material in preventing the passage of bacteria through the mask. The BFE test is performed with an aerosol of Staphylococcus aureus bacteria (particles of approximately $3 \mu \mathrm{m}$ ) at a constant flow rate of $28.3 \mathrm{~L} / \mathrm{min}$ (i.e., a normal breathing flow rate) (ASTM F2101-19 2019). Submicron PFE tests measure the initial particle filtration efficiencies of materials used in medical face masks using monodispersed aerosols of latex particles, usually at 0.1 $\mu \mathrm{m}$ in diameter (ASTM F2299/F2299M-03 2017). Both BFE and PFE must meet the requirements of $\geq 95 \%$ for low-barrier face masks (Level 1) and $\geq 98 \%$ for moderate- and high-barrier face masks (Levels 2 and 3). Differential pressure tests measure the pressure drop across a medical face mask under specific conditions of airflow, temperature, and humidity. The $\Delta P$ metric is an indicator of the breathability of the mask, expressed in $\mathrm{mm}$ $\mathrm{H}_{2} \mathrm{O} / \mathrm{cm}^{2}$ or $\mathrm{Pa} / \mathrm{cm}^{2}$. The ASTM F2100-19e1 (2019) standard requires a $\Delta P$ of $<4.0 \mathrm{~mm}$ $\mathrm{H}_{2} \mathrm{O} / \mathrm{cm}^{2}\left(<39.2 \mathrm{~Pa} / \mathrm{cm}^{2}\right)$ for low-barrier face masks (Level 1) and of $<5.0 \mathrm{~mm} \mathrm{H} \mathrm{H}_{2} \mathrm{O} /$ $\mathrm{cm}^{2}\left(<49.0 \mathrm{~Pa} / \mathrm{cm}^{2}\right.$ ) for moderate- and high-barrier face masks (Levels 2 and 3) (Public Works and Government Services Canada 2020). Lower pressures indicate higher breathability or higher air permeability. The breathability of medical face masks depends on several parameters, such as textile type, the applied finish, the thickness, and the number of layers (Rogister and Croes 2013). Resistance to penetration by a synthetic blood is tested according to the ASTM F1862/F1862M-17 (2017) standard, which requires resistance to synthetic blood at pressures of $80 \mathrm{~mm} \mathrm{Hg}, 120 \mathrm{~mm} \mathrm{Hg}$, and $160 \mathrm{~mm} \mathrm{Hg}$ to qualify for the low-, moderate-, or high-barrier classes, respectively. Flammability tests are based on the rate of flame spread on the material. All medical face masks must meet the requirements for class 1 (Nelson Labs 2019).

\section{Filter Media}

Protective masks have an air filtration system that can be composed of various filter media. The air filter medium is the part of the filter that separates harmful particles from the air. Air filters are used for a wide range of applications, including vehicle air, commercial and residential indoor air (e.g., heating, ventilation, and air-conditioning systems and high-efficiency particulate air (HEPA) filters), clean rooms, laboratory hoods, large baghouse filters, flue gas scrubbers, industrial dust collectors, vacuum cleaner bags, medical protective devices (e.g., respirators and face masks) (Mukhopadhyay 2014), nonmedical face masks, and reusable cloth masks made with a replaceable filter bag. Nonwoven filter media are formed by dry-forming, wet-laid, or combined technologies using many processes depending on the raw material (polymer or fiber source) and filter end use. Dry-forming processes include air-laid web (used to form absorbent materials, normally from cellulose fluff pulp), dry-laid web (used to form many felt materials used for filtration), melt spinning (used to produce spunbonded and meltblown microfibers from melt polymers), and nanofiber spinning (used to produce nanofibers by electrospinning or centrifugal spinning methods) processes. The wet-laid process is used to form webs from wood pulp, vegetable fibers, fibers of polyester, nylon, rayon, or any other material that 
can be dispersed in water, whereas combined technologies are used to form multi-layer composite structures, as in SMS technology, and nonwoven-membrane materials using different processes and/or materials (Hutten 2016).

Air filter media are designed to filter airborne particles using various filtration mechanisms. There are five filtration mechanisms by which airborne particles (aerosols) can be controlled: interception, inertial impaction, Brownian diffusion, gravitational settling, and electrostatic attraction (used in N95 respirators). In N95 respirators and medical face masks, filters must have a porous structure designed to maximize the space for filtration while keeping the differential pressure sufficiently low to maintain breathability (Vaughn and Ramachandran 2002; Institute of Medicine 2006). Medical face masks comprise a combined filtration mechanism: Inertial impaction and interception predominate in the BFE test for the capture of large particles, while Brownian diffusion predominates in the PFE test for submicron particles (Tong et al. 2016). The N95 respirators are also built to capture particles of different sizes: Large particles $(>1 \mu \mathrm{m})$ are captured by interception and inertial impaction, while small particles $(<0.1 \mu \mathrm{m})$ are captured by Brownian diffusion, and both small and large negatively charged particles can be captured by electrostatic attraction, which has the advantage of maintaining a low airflow resistance (Institute of Medicine 2006). Protective masks generally use a filtering gradient from the largest to the smallest particles through the mask. This way, the first layer of the filter captures the larger particles and prevents clogging of the pores in the subsequent layers.

Hutten (2016) divided the raw materials used for filter media into four overlapping categories: polymers, fibers, resins and binders, and additives. Polymers used in nonwoven materials include fibers (e.g., meltblown and spunbonded polypropylene, cellulose from wood pulp and vegetable fibers, and regenerated cellulose or rayon), resins, and additives. Fibers comprise natural fibers (e.g., wood pulp, vegetable fibers, and cotton), biofibers (e.g., rayon and lyocell), and synthetic fibers, to name only the most pertinent for mask manufacturing. The most important physical characteristics of fibers for use in filter media are diameter, length, aspect ratio (length-to-diameter ratio), density, linear density (or fiber coarseness, weight in $\mathrm{mg}$ per $100 \mathrm{~m}$ of fiber), cross-section shape, internal structure (cellular or solid), and strength properties, which include tensile strength, breaking length, stretch or elongation, and stiffness. The ideal properties of the fibers are those that optimize the bulk, air permeability, and pore size of the filter media. When designing filters, the goal is to maximize bulk and air permeability to permit breathability while minimizing pore size to improve filtration efficiency. However, these properties are not directly compatible, as thin fibers provide high density, small pore size, and high filtration efficiency to filter media, but they provide low air permeability. Conversely, coarse fibers provide high bulk and permeability, but they lead to large pore size and thus offer poor filtration efficiency for filter media. In general, the spunbonded web of protective masks is formed by coarse fibers, whereas the fibers are much smaller in the meltblown web. Spunbonded fibers have diameters ranging from $1 \mu \mathrm{m}$ to $50 \mu \mathrm{m}$ (ideal range is from $15 \mu \mathrm{m}$ to $35 \mu \mathrm{m}$ ) and basis weights (grammage) of the filters ranging from $5 \mathrm{~g} / \mathrm{m}^{2}$ to $800 \mathrm{~g} / \mathrm{m}^{2}$ (typically between 10 $\mathrm{g} / \mathrm{m}^{2}$ and $20 \mathrm{~g} / \mathrm{m}^{2}$ ). Their web thicknesses range from $0.1 \mathrm{~mm}$ to $4.0 \mathrm{~mm}$ (typically between $0.2 \mathrm{~mm}$ and $1.5 \mathrm{~mm}$ ), and they are characterized by high strength-to-weight ratios compared to other structures and high liquid retention capacities. Meltblown fibers have diameters ranging from $0.5 \mu \mathrm{m}$ to $30 \mu \mathrm{m}$ (typically between $2 \mu \mathrm{m}$ and $7 \mu \mathrm{m}$ ) and basis weights of the filters between $8 \mathrm{~g} / \mathrm{m}^{2}$ and $350 \mathrm{~g} / \mathrm{m}^{2}$ (typically between $20 \mathrm{~g} / \mathrm{m}^{2}$ and 200 
$\mathrm{g} / \mathrm{m}^{2}$ ) (Hutten 2016). These microfibers have high surface areas for good filtration, smooth textures, and circular cross-sections (Malkan and Wadsworth 1993; Hutten 2016).

The aspect ratio affects the quality and performance in nonwoven webs. In general, synthetic microfibers form highly porous webs and are water repellent, but they are advantageous in filter media because they provide low pressure drop and low wettability, due to a low surface energy. Resins and binders for face masks must provide softness to give greater comfort for skin contact and have skin-friendly properties. Additionally, additives may be used in nonwoven filters, including adsorbent materials (e.g., activated carbon-many replaceable filter cartridges for non-medical face masks are constructed with an activated carbon filter layer), flame retardants (required for cellulose-based filters), water repellents (important for the outer layer of masks), antimicrobial agents, and inks and colorants (used for aesthetic and operational purposes) (Hutten 2016). Debonding and softening agents may be particularly interesting for cellulose-based filters used in face masks. Debonder technology is used in paper products, e.g., tissue paper, to prevent excessive bonding between one cellulose fiber and another and to improve the smoothness of the paper (Furman, Jr. et al. 2013). Debonders provide surface smoothness and increased softness, bulk, and sheet flexibility, among other advantages, to paper sheets (Solenis 2015).

Filter media properties can be affected by several factors related to fiber characteristics (synthetic or natural source, chemical composition, diameter, geometry, specific surface, and density), filter characteristics (thickness, density, bulk, porosity, and pore size distribution) (Vaughn and Ramachandran 2002), filtration velocity (based on flow rate and surface area), filtration mechanisms, and operational conditions (temperature and humidity) (Mostofi et al. 2010). The main properties of filter media are determined according to Eqs. 1 to 6.

The filtration efficiency $(E)$ (expressed in \%) is calculated by Eq. 1,

$$
E=\left(1-\frac{N_{\text {down }}}{N_{\text {up }}}\right)
$$

where $N_{\text {down }}$ and $N_{\text {up }}$ are the downstream and upstream number concentrations of the aerosol particles, respectively (Long et al. 2018; Lu et al. 2018; Pan et al. 2019).

The pressure drop across the filter $(\Delta P)(\mathrm{Pa})$ is determined by the difference between the upstream $\left(P_{\text {up }}\right)$ and downstream $\left(P_{\text {down }}\right)$ pressures (Lu et al. 2018; Ma et al. 2018; Nie et al. 2020a).

In addition to standard filtration efficiency and pressure drop tests to determine the filter media properties of $\mathrm{N} 95$ respirators and medical face masks, a filtration quality factor $(Q)$ (generally expressed in $\mathrm{Pa}^{-1}$ ) is commonly used and calculated as shown in Eq. 2 (Mao et al. 2008; Alexandrescu et al. 2016; Long et al. 2018). Generally, large $Q$ values indicate better filter quality, which conjugates high filtration efficiency (low particle penetration) with low pressure drop (high breathability) (Zhao et al. 2020).

$$
Q=-\frac{\ln (1-E)}{\Delta P}
$$

Air permeability is the airflow rate measured through a specific area of the filter media at a specific pressure drop and is generally expressed in $\mathrm{cm}^{3} /\left(\mathrm{s} \cdot \mathrm{cm}^{2}\right), \mathrm{ft}^{3} /\left(\mathrm{min} \cdot \mathrm{ft}^{2}\right)$, or cfm. The test is performed by an automatic air permeability testing apparatus according to the ASTM D737-18 (2018) standard. Like the pressure drop test, is an indicator of breathability. The airflow depends on $\Delta P$ and filter thickness $(t)$ and is measured by the equation proposed by Whitaker (1986) (Eq. 3), 


$$
v_{0}=-\frac{k}{\mu} \frac{\Delta P}{t}
$$

where $v_{0}$ is the airflow velocity, $k$ is the permeability constant, and $\mu$ is the viscosity of the air (Pan et al. 2019). The air permeability can thus be adjusted by changing the basis weight, thickness, and/or density of the filter. For instance, as filter thickness decreases, air permeability increases (low pressure drop), although the filtration efficiency decreases (Nie et al. 2020a).

The apparent density and porosity both affect the filtration efficiency and pressure drop of the filter media. The density of the filter $\left(\rho_{\mathrm{f}}\right)\left(\right.$ expressed in $\left.\mathrm{g} / \mathrm{cm}^{3}\right)$ is calculated from the ratio of basis weight (BW) and $t$ (Eq. 4),

$$
\rho_{\mathrm{f}}=\frac{B W}{t}
$$

where $B W$ is the weight of a unit area, typically measured in $\mathrm{g} / \mathrm{m}^{2}$, while $t$ is often measured in $\mu \mathrm{m}$ (Hutten 2016). Filter media used for disposable applications are produced at a low basis weight, e.g., approximately $25 \mathrm{~g} / \mathrm{m}^{2}$ in $\mathrm{N} 95$ respirators and medical face masks (Zhao et al. 2020).

The bulk $\left(\beta_{\mathrm{f}}\right)$ is also used to characterize the filter and corresponds to the inverse of the density, expressed in $\mathrm{cm}^{3} / \mathrm{g}$ (Eq. 5) (Hutten 2016),

$$
\beta_{\mathrm{f}}=\frac{1}{\rho_{\mathrm{f}}}=\frac{t}{B W}
$$

The porosity $(\varepsilon)$ of the filter can be calculated from the basis weight, thickness, and fiber density ( $\rho$ fiber), as shown in Eq. 6 (Long et al. 2018). The pore properties (size and distribution) are affected by fiber type (synthetic or natural), fiber dimensions (micro- or nano-scale), and, particularly for pulp fiber sheets, drying conditions to remove excess water from wet-formed sheets (Sim and Youn 2016).

$$
\varepsilon=1-\frac{B W}{\rho_{\text {fiber }} t}
$$

The strength properties of filter media include in-plane and out-of-plane properties. In-plane properties comprise tensile properties (tensile strength, stretch or elongation, tensile energy absorption, and tensile stiffness), while out-of-plane properties include bending stiffness, burst strength, internal bond strength, and Z-direction compression. Other properties of filter media are also important. For example, water resistance is important principally for moisture-absorbing materials such as cellulose fibers, as dimensional changes due to moisture absorption affect the integrity of the filter and cause pore closure, increasing flow resistance and decreasing filtration performance (Hutten 2016).

\section{OVERVIEW OF CELLULOSE AND NANOCELLULOSE FOR MASK PRODUCTION}

Many filtration technologies and new materials used in face masks have been studied since the occurrence of the COVID-19 pandemic. Among the most important filtration technologies are nanotechnology, membrane technology, and composite and impregnated media structures, as well as adsorbent/absorbent, electrostatic, and antimicrobial media (Hutten 2016). Cellulose has great potential as one of the most versatile and renewable materials suitable for such applications, either through the use of 
nanocellulose or through the design of functional composite structures, as discussed in this section.

\section{Wood Pulp Fibers}

Wood pulp fibers are biosynthesized composites made of spirally wound cellulose microfibrils, which are formed from cellulose chains made of several glucose molecules and assembled through hydrogen bonds and van der Waals intermolecular interactions (Tavakolian et al. 2020). Wood-derived cellulose is composed of crystalline (in a high portion of approximately 65\%) and amorphous regions, both with accessible and nonaccessible parts for moisture sorption, pulping, and chemical modifications. The accessible cellulose comprises the surfaces of crystalline cellulose and almost the entire amorphous regions (Rowell et al. 2005). Wood pulp fibers differ from synthetic fibers usually used in protective masks in several ways. Firstly, pulp fibers have irregular shapes and a hollow cellular structure in the cross-section, while synthetic fibers have a regular and solid rounded structure (Pan et al. 2019). Additionally, thermoplastic synthetic fibers are hydrophobic, while cellulose fibers are hydrophilic. Masks containing cellulose or paper are not compatible with certain vaporization and sterilization procedures used to disinfect single-use N95 respirators in case of shortage (Bernier et al. 2020). Therefore, cellulosebased masks must be designed for single-use and provide antimicrobial and hydrophobic properties, as discussed in a later section.

The main attributes of wood pulp fibers, such as length, coarseness, strength, and uniformity, are largely dependent on the single-fiber characteristics of the raw material (length, diameter, wall thickness, and microfibrillar angle (MFA)) (Watson and Bradley 2009), which vary considerably between wood species. These characteristics also vary at different scales between trees, between annual growth rings of a tree, and within individual growth rings (Schweingruber 2007). Moreover, site, silvicultural treatments, and several other factors affecting environmental conditions can affect the characteristics of the raw material (Macdonald and Hubert 2002). In general, softwood pulp fibers are typically longer $(3.5 \mathrm{~mm}$ to $5.0 \mathrm{~mm})$ and coarser $(40 \mu \mathrm{m}$ in diameter), with an aspect ratio of approximately 100, whereas hardwood pulp fibers are generally $1 \mathrm{~mm}$ to $2 \mathrm{~mm}$ length and $22 \mu \mathrm{m}$ in diameter, with an aspect ratio of 90. Both pulp fiber types are important for the filter media because softwood pulps provide bulk, strength, and permeability, whereas hardwood pulps provide filtration efficiency (Hutten 2016). Fiber coarseness is the relative mass of the cell wall or weight in mg of fiber per unit length, which can be measured using an optical analyzer. Lower fiber coarseness provides higher sheet tensile strength, greater bonding area, and more fiber per ton of pulp (Watson and Bradley 2009). The angle of microfibrils in the $\mathrm{S}_{2}$ layer of the cell wall also varies at different scales within and between trees (Jordan et al. 2005; Auty et al. 2018). This property of the cell wall may also affect the mechanical properties of paper sheets, such as tensile strength, stretch, modulus of elasticity, and stiffness. A study with loblolly pine kraft pulp showed that fibers with high MFA are flexible and soft, and they have high stretch and a low elastic modulus, whereas those with low MFA have low stretch and a high elastic modulus (Courchene et al. 2006).

Wood pulps are obtained by a chemical, mechanical, or semi-chemical pulping process. The degree of purity (measured by the $\alpha$-cellulose content) and contamination (lignin) of cellulosic fibers, which vary depending on the pulping process, affect the bulk and permeability of filter media. High-purity pulp has weak bonding and low strength properties, but it provides high bulk and permeability, two important properties for filter media that are directly affected by the level of purity of the wood pulp (Hutten 2016). 
Chemical pulping includes the alkaline kraft, the acidic sulfite, and the organosolv processes. The kraft process uses an aqueous mixture of sodium hydroxide $(\mathrm{NaOH})$ and sodium sulfide $\left(\mathrm{Na}_{2} \mathrm{~S}\right)$ (white liquor) to break down the molecules of lignin under elevated temperature and pressure in a digester and separate strong cellulose fibers (pulp) (Bajpai 2017a). Kraft pulp is preferred for filter media because of its strength properties (Hutten 2016), which are particularly important for N95 respirators and medical face masks to maintain structural integrity of the material during use. The sulfite process uses sulfurous acid $\left(\mathrm{H}_{2} \mathrm{SO}_{3}\right)$ and bisulfite $\left(\mathrm{HSO}_{3}{ }^{-}\right)$ions to solubilize the lignin; the pulp mechanical properties from this process are inferior to those of the kraft process (Bajpai 2017a). A special grade of chemical pulp, named "dissolving pulp" or "dissolving cellulose," can be obtained from the kraft or sulfite process with an acid pre-hydrolysis step to remove hemicelluloses; this pulp has a high chemical purity and is used in the manufacture of regenerated cellulose or rayon to form textile fibers like viscose or lyocell (Polymer Properties Database 2015; Chen et al. 2016a). The organosolv processes use organic solvents such as aromatic alcohols (phenols) or aliphatic alcohols (e.g., ethylene glycol, methanol, ethanol, butanol, or glycerol) and an acid catalyst (e.g., hydrochloric acid ( $\mathrm{HCl})$ or sulfuric acid $\left(\mathrm{H}_{2} \mathrm{SO}_{4}\right)$ ) generally at temperatures less than $185{ }^{\circ} \mathrm{C}$, although higher temperatures may also be used depending on the process and the raw material; these processes provide access to higher-grade lignin than that of the kraft process or sulfite process while still obtaining relatively pure cellulose fibers as the main product (Yoya and Stevanovic 2018). Additionally, a new organosolv process using a Lewis acid catalyst has been developed and patented recently, and it permits more efficient recovery of high-purity lignin applicable in many industrial domains (Stevanovic and Koumba Yoya 2019). This new approach enables better use of lignin as a by-product of the pulping process.

Mechanical pulping consists entirely (or for the most part) of a mechanical process using mechanical force, combined with pressure and temperature, to separate the wood fibers. In some cases, chemicals may be added to the process (chemical-thermomechanical pulp). Mechanical pulping includes pressurized groundwood and thermomechanical pulp processes, which generate fibers and paper with lower strength compared to chemical pulps. Mechanical pulps have lower purity and more contaminants than chemical pulp, and they are therefore less suitable for N95 respirators and face masks. Fluff pulp, also known as fluffing or comminution pulp, is made by a chemical, mechanical, or combined chemical-mechanical process, usually bleached, and used as an absorbent medium in disposable diapers, bed pads, and personal hygiene products (American Forest \& Paper Association 2019). Fluff pulp has high porosity, and the hydrophilic properties of cellulose make it a good absorbent material (Rom et al. 2007). Fluff pulp also gives bulk to filter media and is an important fiber raw material for wet-laid cellulose filter media. Mercerized pulp, which is obtained by a post-treatment with caustic soda (alkaline solution) of fully bleached pulp (usually southern bleached softwood kraft (SBSK) pulp), has very high purity (more than 99\% $\alpha$-cellulose) and can confer high bulk and high porosity (Hutten 2016) in filter media and nonwoven applications. Because the purity of the pulp is a crucial characteristic for filtration purposes, bleached chemical pulp is generally preferred for the manufacture of N95 respirators and medical face masks, as the bleaching process eliminates all impurities from the pulp.

There are few studies related to the use of cellulose-based filters in protective masks. However, research has shown that filters produced from wet beating of northern bleached softwood (NBSK) and hardwood (NBHK) kraft pulps followed by partial freezedrying present filtration efficiency and pressure drop values close to those typical of N95 
respirators (Mao et al. 2008). The authors produced single-layer filters from wood pulp by two forming methods (dry and wet forming), as well as three-layer filters composed of NBSK pulp in the middle layer and a commercial fluff pulp in the outer and inner layers. Wet-formed filters produced from NBHK pulp had the best performance. In this case, $Q$ values were close to those of commercial NIOSH-certified N95 filters at the same face velocity (flow rate) of $12 \mathrm{~cm} / \mathrm{s}$ (corresponding in practice to the breathing that occurs during a heavy workload). Their results also showed that greater beating provided higher capture efficiency and a greater pressure drop to the filters, due to greater surface area and smaller fibril diameter. For a given beating energy, a greater basis weight also provided increased capture efficiency and pressure drop (Mao et al. 2008). In short, these results showed that fibrillated cellulose provides the desired filtration efficiency but reduces air permeability, showing that particular attention should be paid to controlling air permeability in the manufacture of cellulose-based masks. In this way, mixed softwood and hardwood kraft pulps could provide a favorable compromise between filtration efficacy and air permeability. Another study proposed a method to form a spider-web-like structure in fibrillated-cellulose-based air filters to improve filtration performance (Lu et al. 2018). The fibrillated cellulose was prepared from a suspension of bleached softwood kraft pulp fibers. The spider-web-like structure was obtained from a fibrillated cellulose / water / tert-butyl alcohol (TBA) suspension followed by freeze-drying. The spider-weblike cellulose-based filter exhibited a filtration efficiency greater than $99 \%$ for the MPPS, regardless of the TBA content (ranging from $0 \%$ to $40 \%$ ), while pressure drop increased with increasing TBA content. The mechanical properties of the cellulose-based filters were reduced with increasing TBA, which is explained by the weakness of the intermolecular hydrogen bonding interactions between adjacent microfibrils with increased TBA. These results highlight the high filtration potential of microfibrillated cellulose by the construction of spider-web-like structures in cellulose-based filters.

A recent study has compared meltblown polypropylene, as found in commercial N95 respirators and medical face masks, to various paper-based products (paper towel, tissue paper, and copy paper), among other materials (Zhao et al. 2020). That study showed that the electret meltblown polypropylene of N95 respirators had a 9.0 Pa pressure drop for $95.94 \%$ initial filtration efficiency and a $Q$ of $162.7 \mathrm{kPa}^{-1}$, whereas non-electret meltblown polypropylene of medical face masks had $34 \mathrm{~Pa}$ and $16 \mathrm{~Pa}$ pressure drops for $33 \%$ and $18 \%$ filtration efficiencies and $Q$ factors of $5.0 \mathrm{kPa}^{-1}$ and $5.5 \mathrm{kPa}^{-1}$. Compared to medical face masks, paper towel and tissue paper showed moderate filtration performances of $10.4 \%$ and $20.2 \%$ for similar pressure drops and $Q$ values of $4.3 \mathrm{kPa}^{-1}$ and $5.1 \mathrm{kPa}^{-1}$, respectively. Meanwhile, copy paper had a high filtration efficiency but a very high and unsuitable pressure drop caused by higher bulk density and low porosity. The authors stated that paper towels and tissue paper could be inserted into cloth masks as a filter to increase their effectiveness; however, they have the disadvantage of low mechanical strength. These results serve as a reference for future work on paper-based filters.

\section{Wood-derived Nanocellulose}

Nanocellulose technology has great potential for filtering purposes, as it provides materials not only high mechanical filtration efficiency but also the possibility of functionalization into smart materials. Filters composed only of cellulose pulp fibers form relatively large pores due to their micro-scale dimensions in width. However, cellulose nanostructures, which are obtained from pulp fibers by mechanical or chemical treatments, allow better control of pore characteristics, so the filtration efficiency and mechanical 
properties of filters can be improved. The morphological characteristics and properties of nanocellulose, such as its high specific surface, can improve absorption and capture of small particles because of the small pore size (Sim and Youn 2016), and thus filter thickness can be reduced to allow better breathability (Chua et al. 2020). Moreover, nanocellulose provides superior functionalities (e.g., antimicrobial properties) to the filter media in comparison with cellulose pulp and other micro-scale polymers (Bajpai 2017b). Nanocellulose from wood pulp also has demonstrated biocompatibility and non-toxic properties for use in materials that are in contact with human skin (Alexandrescu et al. 2013).

Nanocellulose is often used as a common term for isolated cellulosic materials with at least one dimension in the nanometer range. It can be obtained from lignocellulosic fibers but also from algae, tunicates, and bacteria (Khalil et al. 2014). Nanocelluloses obtained from wood pulp fibers are generally grouped into either cellulose nanocrystals (CNCs) or cellulose nanofibrils (CNFs). However, a new generation of nanocellulose materials has emerged in recent years, which includes hairy nanocellulose (HNC), a new type of CNC (van de Ven and Sheikhi 2016; Tavakolian et al. 2020), and cellulose filaments (CFs), a fibrillated material with unique morphological characteristics (Hamad et al. 2019).

Cellulose nanocrystals are biodegradable rigid nanorods composed only of the crystalline parts of the cellulose, ranging in size from $2 \mathrm{~nm}$ to $20 \mathrm{~nm}$ in diameter and 100 $\mathrm{nm}$ to $600 \mathrm{~nm}$ in length (Beck-Candanedo et al. 2005; Tuukkanen and Rajala 2018), having a low aspect ratio $(<100)$ (Bharimalla et al. 2015). Cellulose nanocrystals have strong mechanical properties (tensile strength of $7500 \mathrm{MPa}$ and Young's modulus of $100 \mathrm{GPa}$ to $140 \mathrm{GPa})$ due to high intermolecular bonding, very high specific surface $\left(150 \mathrm{~m}^{2} / \mathrm{g}\right.$ to $250 \mathrm{~m}^{2} / \mathrm{g}$ ), and high heat stability (low thermal expansion coefficient), which makes them suitable for tissue engineering and cargo carrying (Tavakolian et al. 2020). Due to these properties, CNCs also have high potential versatility in terms of functionalization and modification (Trache et al. 2020). Cellulose nanocrystals are commonly obtained by concentrated acid hydrolysis using sulfuric acid to react with wood pulp under controlled conditions of acid-to-pulp ratio and temperature (Hamad et al. 2019), although other means of production can also be used (Miller 2018). Cellulose nanocrystals are used in various forms, e.g., powder, gel, or film (membrane), usually to make lighter and stronger materials with greater durability in a wide range of applications, including paints, packaging, cosmetic bases, pigments, food modifiers, sensors, biomedical sciences, and composites (Tavakolian et al. 2020). Regarding filter applications, CNCs have a demonstrated capacity to improve filtration efficiency with a low pressure drop in poly(vinyl alcohol) (PVA) / CNC composite nanofibrous filters produced by electrospinning for HEPA filters (Zhang et al. 2019a). The main sources of CNCs are wood pulp, cotton, hemp, flax, wheat straw, rice straw, mulberry bark, ramie, tunicin, algae, and bacteria, among others (Klemm et al. 2011).

Hairy nanocellulose is a new class of nanocellulose, formed by nanorods made of crystalline parts and also amorphous chains ("hairs") protruding from both ends, which provides high colloidal stability and unique physicochemical properties, resulting in a wider range of applications than conventional CNCs (van de Ven and Sheikhi 2016). Hairy nanocelluloses are synthesized by oxidizing, solubilizing, and cleaving the amorphous regions of cellulose fibrils (Tavakolian et al. 2020). There are different types of HNCs with neutral, negative, and positive charge contents to be chosen for various potential applications (Tavakolian et al. 2020), such as transparent films (stronger and more flexible than those made using conventional CNCs), superhydrophobic films (e.g., crosslinked with 
a diamine), security packaging (to manufacture smart coatings and packaging based on green nanomaterials), heavy metal ion scavengers, scavengers of non-ionic pollutants, cellulose hydrogels (hydrophilic polymer networks), humidity switches, polymer reinforcement, rheology modifiers, flocculants, directed metal nanoparticle synthesis, and biomimetic mineralization (van de Ven and Sheikhi 2016).

Cellulose nanofibrils are long slender rod-like particles consisting of alternating crystalline and amorphous cellulose regions. According to a Technical Association of the Pulp and Paper Industry (TAPPI) report, the terms CNF (or nanofibrillated cellulose, NFC) and microfibrillated cellulose (MFC) are used interchangeably, with an overlap in the diameter specifications; while some of these materials contain only particles smaller than $100 \mathrm{~nm}$ in diameter, others contain a mixture of particles ranging from the nanoscale to the microscale (Miller 2018). Cellulose nanofibrils are produced from cellulose pulp fibers using an energy-intensive mechanical treatment, although they are usually chemically or enzymatically pretreated to reduce energy consumption. The most commonly reported pretreatment in scientific studies is a 2,2,6,6-tetramethylpiperidine-1-oxyl (TEMPO)mediated oxidation of cellulose fibers, which oxidizes the primary hydroxyl groups at the C6 position of the glucose units and converts them to carboxyl groups (uronic acid) (van de Ven and Sheikhi 2016). Cellulose nanofibrils have a high aspect ratio (> 100) (Bharimalla et al. 2015) and a high specific surface area, with regions of hydroxylated surface chemistry for possible chemical modification (Klemm et al. 2011) interspersed with the crystalline phase (Dimic-Misic et al. 2018). However, the degree of surface chemistry and fibril dimensions depend on the CNF source or origin, pre-treatment, and fibrillation procedures (Alexandrescu et al. 2013). The main sources of CNFs are wood pulps, sugar beet, potato tuber, hemp, and flax fibers (Klemm et al. 2011).

Cellulose nanofibrils and CFs are both fibrillated materials; however, CFs are morphologically different from CNFs. Cellulose filaments are longer and are heterogeneous, comprising cellulose fibrils and fiber fragments (Hamad et al. 2019), and they have a higher aspect ratio (greater than 1000) than that of CNFs (Miller 2018). Cellulose filaments can be produced from all types of wood pulps, bleached or unbleached, using a mechanical refining method. Kruger Biomaterials Inc. produces CFs in its commercial plant in Trois-Rivières, Quebec, Canada, using a proprietary technology licensed from FPInnovations Inc., with an annual production capacity of up to 6,000 t of a product traded under the name FiloCell ${ }^{\circledR}$. This product is used as a reinforcement additive for various paper and tissue grades to improve wet and dry strength, consistency of mechanical strength, and filler retention (Kruger Biomaterials 2018). FiloCell ${ }^{\circledR}$ CFs from Kruger are produced from kraft wood pulp without further application of chemicals or enzymes, with dimensions ranging from $0.1 \mathrm{~mm}$ to $2.0 \mathrm{~mm}$ in length, $80 \mathrm{~nm}$ to $300 \mathrm{~nm}$ in width, and $40 \mathrm{~nm}$ to $100 \mathrm{~nm}$ in thickness (a single kraft pulp fiber produces approximately $1000 \mathrm{CFs}$ ). Other characteristics of FiloCell ${ }^{\circledR} \mathrm{CFs}$ include a high specific surface of 80 $\mathrm{m}^{2} / \mathrm{g}$, a density of $1.45 \mathrm{~g} / \mathrm{cm}^{3}$, and purity; and they are biodegradable, compostable, thixotropic in solution, lignin-free, and available in several forms (wet pulp, dry and dispersed fluff, water suspension, etc.) (Kruger Biomaterials 2018). Cellulose filaments have physical and chemical advantages over kraft pulp, which is often used as reinforcement for weaker pulps. Cellulose filaments have a higher aspect ratio than softwood kraft pulp and more hydroxyl groups on the surface for the same weight of material, leading to improved mechanical properties in many materials, such as polymer composites, cement and concrete products, and paper and tissue paper products (Fairbank 2020). 
For filter applications, wood-based nanocellulose materials have been used, for example, in the development of mixed wood pulp / CNF filters (Alexandrescu et al. 2016; Sim and Youn 2016), wood pulp / PET composite filters for air filtration (Long et al. 2018), and ultrafiltration membranes (Wang et al. 2013, 2019) using adsorption mechanisms to remove bacteria, viruses, and heavy metal ions from water (Wang et al. 2013). Sim and Youn (2016) investigated the structures and properties of porous sheets produced from pulp fiber (hardwood and softwood bleached kraft pulp) or PET mixed with CNFs. The mixing ratio of CNFs ranged from $0 \%$ to $50 \%$ at intervals of $10 \%$ for each fiber type. Cellulose nanofibrils were prepared from a commercial hardwood bleached kraft pulp and had an average width of $38 \mathrm{~nm}$. Sheets were formed by a wet-laid forming method and dried by different methods (cylinder or freeze-drying). All sheets had a similar basis weight of 36 $\mathrm{g} / \mathrm{m}^{2} \pm 1 \mathrm{~g} / \mathrm{m}^{2}$ and densities ranging from $0.21 \mathrm{~g} / \mathrm{cm}^{3}$ to $0.58 \mathrm{~g} / \mathrm{cm}^{3}$, depending on the fiber mix, CNF ratio, and drying conditions. The addition of CNFs improved considerably the mechanical properties (tensile strength and elastic modulus) of the porous sheets for all fiber combinations. Porous sheets formed from a combination of hardwood bleached kraft pulp fibers and CNFs showed a high filtration efficiency of $99.94 \%$ but also a high pressure drop. The air permeability of the porous sheets decreased as the amount of CNFs increased. However, the application of a freeze-drying method increased porosity and pore size and improved the air permeability of the sheets. The same study also reports the effects of fiber morphology on the apparent density, porosity, and thickness of the filters and, consequently, on their filtration efficiency, pressure drop, and air permeability properties. The PET fibers formed bulkier sheets, while pulp fibers formed denser sheets due to their dimensions and internal structure (solid or cellular). Synthetic fibers have a solid, filled structure, while pulp fibers have a tubular structure with cellular lumens, resulting in greater compactness and density and, therefore, less bulk and porosity than PET fibers. Alexandrescu et al. (2016) used CNFs from bleached eucalypt kraft pulp to form CNFbased filters. Cellulose nanofibrils were prepared by the mechanical fibrillation method, with and without TEMPO-mediated oxidation before fibrillation. In the filter formation, CNFs are dispersed using water, but then water removal is one of the challenges for the production of CNF filters because fibrils tend to clump together during drying as they form hydrogen bonds, leading to compact structures, a process known as cellulose hornification. To solve this issue, a freeze-drying process was applied. The TEMPO-treated CNF filter had the best performance $\left(Q=0.025 \mathrm{~Pa}^{-1}\right)$ compared to the untreated CNF filter $(Q=0.015$ $\left.\mathrm{Pa}^{-1}\right)$. The filtration efficiency (46\%) and pressure drop (25 $\mathrm{Pa}$ at $5.3 \mathrm{~cm} / \mathrm{s}$ face velocity) of the TEMPO-treated CNF filters were close to those found by Zhao et al. (2020) for meltblown polypropylene found in medical face masks. Long et al. (2018) studied the effects of different proportions of lyocell MFC, ranging from $0 \%$ to $20 \%$ in $5 \%$ intervals, on the filtration efficiency and pressure drop of softwood pulp / PET composite filters. Softwood pulp fibers varied from 55\% to 75\%, while PET fibers had a constant proportion of $25 \%$ in the filter composition. All composite filters had a basis weight of $105 \mathrm{~g} / \mathrm{m}^{2} \pm 2$ $\mathrm{g} / \mathrm{m}^{2}$, but filter thickness and porosity decreased slightly as the fraction of MFC increased. Both the filtration efficiency for particles ranging from $30 \mathrm{~nm}$ to $2 \mu \mathrm{m}$ in size and the pressure drop increased with the increase in the fraction of MFC. The authors reported that the optimal fraction of MFC was to 5\%, as larger fractions tented to decrease the uniformity and $Q$ factor of the composite filters. For the application of CFs in filter media, an FPInnovations patent recommends a proportion of up to 10\% (Drolet et al. 2017); however, further research is needed to assess the potential of CFs to improve the properties of N95 respirators or face masks. 


\section{ANTIMICROBIAL TECHNOLOGIES APPLICABLE TO CELLULOSE FIBERS}

Antimicrobial agents are used to provide biocidal (pathogen elimination) or biostatic (pathogen growth inhibition) activities to many materials. Such properties are important for protective masks because they protect the wearer against harmful bioaerosols, in addition to offering greater comfort to the skin, as the prolonged use of a face mask can cause skin irritation. Additionally, by increasing the temperature and humidity between the mask and the skin, prolonged use creates an environment favorable to the proliferation of fungi and bacteria. As cellulose is a hydrophilic and biodegradable material, cellulose-based masks require antimicrobial treatments, preferably with antiviral properties, given the current context of the COVID-19 pandemic.

Cellulose surfaces, having multiple carboxylic acid groups, have an intrinsic negative charge, which offers the opportunity to perform cationic modifications by adding positively charged materials for antimicrobial functionalization (Alavi 2019). There are many natural, synthetic, organic, and inorganic antimicrobial agents with an affinity for cellulose that can potentially be used in protective masks. These include natural bioactive compounds (e.g., polyphenols, terpenoids, organic acids, and polysaccharides), metalcontaining materials, inorganic salts (e.g., quaternary ammonium compounds (QACs)), synthetic polymers (e.g., N-halamines and polyhexamethylene biguanide (PHMB)) (Ristić et al. 2011; Timofeeva and Kleshcheva 2011), and composites thereof, including MOFs, which are regarded as the most innovative today (Chua et al. 2020; Nie et al. 2020a). As highlighted in this section, several of them have antiviral properties, whereas other nanomaterials such as graphene can act as an enhancing agent for other well-known antiviral agents, e.g., silver nanoparticles (Ag NPs).

\section{Natural Products}

\section{Polyphenols and terpenoids}

Many natural compounds have intrinsic antiviral properties, with proven efficacy against some types of coronaviruses, but they are not yet proven against SARS-CoV-2. An extended list of plant-based products and their mechanisms of action against a large variety of viruses is presented by Lin et al. (2014). Particularly for the coronavirus family, the authors highlight antiviral compounds such as phenolic compounds of Isatis indigotica, amentoflavone (a biflavonoid isolated from Torreya nucifera), myricetin, scutellarein, Houttuynia cordata water extract, and active compounds from Lycoris radiata (lycorine), Artemisia annua (artemisinin), Pyrrosia lingua, and Lindera aggregata. They also note antiviral activity of saikosaponins (A, B, $\mathrm{C}$, and $\mathrm{D})$, which are triterpene glycosides isolated from medicinal plants, against human coronavirus 229E (HCoV-229E). These various compounds inhibit viruses using different mechanisms of action. However, more research is needed to assess the effects of these plant-derived compounds on human health, their economic viability, and safety criteria for their use in protective devices, as the active compounds can vary from one plant to another, depending on local growth, soil conditions, climate, etc. Studies have also reported the antiviral activities of curcumin, found in the rhizome of Curcuma longa, a plant from the ginger family commonly named turmeric (Moghadamtousi et al. 2014), and catechin polyphenols (Catel-Ferreira et al. 2015). For instance, the antiviral properties of catechin polyphenols grafted on a cellulose-based filter for masks was studied by Catel-Ferreira et al. (2015). The authors recomposed masks by replacing the cellulose layer of a commercial Kolmi M24001 medical face mask with one or two layers of a catechin-grafted cellulose filter produced using laccase as an enzymatic 
coupling reagent. The antiviral activities of the filters were tested in liquid media of a viral concentration (T4D bacteriophage virus of Escherichia coli B), and face masks were compared for filtration efficiency. The catechin grafted-cellulose filters showed a great effect on the viral concentration, while a remarkable increase in virus filtration with a moderate airflow resistance was obtained for recomposed masks compared to the original masks. Another study assessed the antifungal properties of a turmeric-based nanomaterial coating on cellulosic cotton fibers (Gargoubi et al. 2020). In this case, cellulose fibers were coated with poly(dopamine), a nanomaterial produced from the final oxidation of dopamine or other catecholamines (Ball 2018), which has biocompatible molecules to enhance the uptake and attachment of bioactive turmeric. The poly(dopamine) interface forms a spider-web-like layer to establish bridges between cellulose fibers and antifungal molecules. The results showed that the turmeric/poly(dopamine)/cellulose composite material inhibited fungal growth, while the morphological characteristics and mechanical properties of the cellulose fibers were preserved (Gargoubi et al. 2020). The composite material could have a potential use in protective face masks to prevent fungal skin infections caused by prolonged mask wear (Hamann 2020).

\section{Organic acids}

Some commercial N95 respirators and medical face masks present an acid-based medium as an antiviral coating. These masks have an antimicrobial outer layer made of polyester or regenerated cellulose fibers treated with citric acid, sometimes combined with other antiviral agents such as $\mathrm{Cu}-\mathrm{Zn}$ ions (Davison 2012; RespoKare 2017; Chua et al. 2020). Citric acid is also used as a cross-linking agent, to reduce the water retention properties of cellulose fibers in paper and textiles (Rom et al. 2007).

\section{Polysaccharides}

Several studies have reported the antimicrobial properties of chitosan, a modified natural carbohydrate derived from chitin found in the exoskeletons of crustaceans, mussels, fungi, insects, and some algae (Ristic et al. 2011). The antimicrobial activity of chitosan is attributed to positively charged amino groups $\left(-\mathrm{NH}_{3}{ }^{+}\right)$that form polycationic compounds in acid media capable of interacting with negatively charged groups of lipopolysaccharides and proteins on the cell surfaces of microorganisms, causing membrane disintegration and damage to the cell wall. However, the antimicrobial capacity of amino chitosan depends on its degree of deacetylation (ranging from 60\% to 95\%), molecular weight, and the ratio between protonated and deprotonated amino groups (Kucharska et al. 2020). Like cellulose, chitosan is one of the most abundant biopolymers on Earth (Ristić et al. 2011). Chitosan is very popular today because it is eco-friendly, renewable, biodegradable, nontoxic, and biocompatible, and further functionalization allows for its use in a wide range of applications (Hahn et al. 2020), including biomaterials and healthcare materials (Vaz et al. 2014). Moreover, chitosan and chitosan derivates can be applied as carriers and linkers of flame-retardant agents and superhydrophobic coatings (Hahn et al. 2020), contributing to two important properties of medical face masks for meeting regulatory requirements. Three-layer non-medical masks, marketed under the name M-Chitosan, composed of an inner antibacterial layer of chitosan are already available on the market (M-Chitosan 2020). The antiviral properties of chitosan nanocomposites, e.g., chitosan nanoparticles / curcumin (Loutfy et al. 2020) and Ag NPs / chitosan (Ling et al. 2013; Mori et al. 2013), and functionalized chitosan (Milewska et al. 2013) have been also investigated. The study conducted by Mori et al. (2013) revealed no antiviral activity of chitosan against the H1N1 
influenza A virus; however, the chitosan matrix had the advantage of preventing the release of Ag NPs, a well-known antiviral agent, from Ag NP / chitosan composites. Meanwhile, Loutfy et al. (2020) showed that chitosan nanoparticles can increase the antiviral effects of curcumin in chitosan/curcumin nanocomposites. Additionally, a cationic chitosan derivate (N-(2-hydroxypropyl)-3-trimethylammonium chitosan chloride, HTCC) showed antiviral activity against human coronavirus NL63 (Milewska et al. 2013). For paper materials, chitosan derivates, e.g., quaternary carboxymethyl chitosan (QCMC), prepared by grafting carboxymethyl groups and quaternary ammonium groups to chitosan chains, have been used as antibacterial agents (Ling et al. 2013). Ahmad et al. (2016) used chitosan to enhance the affinity of cellulose fibers for $\mathrm{Ag}$ ions to produce functional cellulose filter papers. Due to their similar structures, chitosan and cellulose form hydrogen bonds (He et al. 2018). Thus, chitosan provides strong bonding and increased mechanical properties of paper materials (Kucharska et al. 2020). Ling et al. (2013) prepared Ag NP-loaded QCMC / organic montmorillonite (QAOM) nanocomposite coatings for paper surfaces. In addition to greater antimicrobial capacity, QAOM-coated paper exhibited higher tensile, shear, and bursting strengths than uncoated paper. For cellulose-based mask applications, chitosan has often been used in combination with other antiviral technologies to form nanocomposite materials, e.g., Ag NPs / chitosan (Imani et al. 2011) and MOFs/chitosan (Nie et al. 2020a), as presented throughout this section.

\section{Synthetic and/or Inorganic Products}

Metal-containing materials

Some well-known and widely documented antiviral technologies have gained considerable uptake since the occurrence of the COVID-19 pandemic. These include metals and metal compounds of silver $(\mathrm{Ag})$, copper $(\mathrm{Cu})$, and zinc $(\mathrm{Zn})$ used in protective masks, principally for reusable cloth masks made of cotton or synthetic fibers. Many metals and metal compounds (e.g., metal salts and metal oxides) have been shown to be effective antimicrobial agents with antibacterial (Imani et al. 2011; Emam 2019) and/or antiviral properties (Bright et al. 2009; Borkow et al. 2010; Galdiero et al. 2011; Zhou et al. 2020). Bright et al. (2009) found that $\mathrm{Ag}$ and $\mathrm{Ag} / \mathrm{Cu}$ zeolites inactivate enveloped viruses such as coronaviruses by charge-based interactions with their outer lipid envelope membranes. An FDA-approved antiviral N95 respirator is currently commercialized by Nexera Medical SpectraShield ${ }^{\mathrm{TM}}$ using the $\mathrm{Ag} / \mathrm{Cu}$ zeolite technology. Zeolite is a carrier that controls the release of metal ions (Nexera Medical 2020). Copper oxide particles can also be impregnated into N95 respirators without altering their filtration properties, a solution with demonstrated efficacy against the influenza virus (Borkow et al. 2010).

The antiviral properties of Ag NPs against the H1N1 influenza A virus have also been demonstrated; however, the antiviral activity depends on the concentration and size of the nanoparticles. The antiviral effect of Ag NPs was stronger with smaller nanoparticles in the Ag NP / chitosan composites, and antiviral activity increased as the concentration of Ag NPs increased (Mori et al. 2013). Since 2012, Biofriend ${ }^{\mathrm{TM}}$ Biomask $^{\mathrm{TM}}$ has been offering disposable antiviral surgical N95 respirators and medical face masks comprising a cellulose/polyester layer with positively charged $\mathrm{Cu} / \mathrm{Zn}$ ions (Davison 2012). Many companies provide metal-based antimicrobial technologies, mainly Ag, because of its nontoxicity, eco-friendliness, high thermal stability, and antiviral properties; however, like for $\mathrm{Cu}$ and $\mathrm{Zn}$, the high cost of $\mathrm{Ag}$ makes the mask-making process more costly. Dupont Silvadur ${ }^{\mathrm{TM}}$ technology uses $\mathrm{Ag}$ ions to neutralize microorganisms in textiles that are currently used in non-medical cloth (cotton) masks for the general public. 
The antibacterial properties of Ag NPs capped with polyacrylic acid (PAA) combined with chitosan have been investigated in wood pulp filters (Imani et al. 2011). The authors used a layer-by-layer technique to impregnate filters made of bleached softwood kraft pulp fibers with Ag NPs / PAA / chitosan and showed that, in addition to being efficient, the antibacterial layer did not affect the tensile strength or pore structure of the filter.

\section{MOFs}

Metal-organic frameworks are defined as organic-inorganic hybrid crystalline porous materials composed of a regular array of positively charged metal ions or clusters surrounded by organic ligands (Berger 2020). They are a new class of materials with key advantages compared to other metal compounds (Chua et al. 2020). The metal ions construct nodes that assemble the organic ligands via a molecular building block approach to form a hollow frame structure with an ultra-high surface area. Many structures of MOFs can be synthesized using different metal ions and organic ligands, with numerous applications (Berger 2020). For instance, zeolitic imidazolate framework-8 (ZIF-8), copper(II)-benzene-1,3,5-tricarboxylate (Cu-BTC) MOF (MOF-199), and Ag-based MOFs (Ag-MOFs) are used for antibacterial applications (Ma et al. 2018). A recent study investigated the potential of MOF-paper materials as antibacterial composites for air filtration (Nie et al. 2020a). The authors used ZIF-8, a three-dimensional framework designed with zinc nitrate hexahydrate $\left(\mathrm{Zn}\left(\mathrm{NO}_{3}\right)_{2} \cdot 6 \mathrm{H} 2 \mathrm{O}\right)$ ions and 2-methylimidazole (2$\mathrm{H}-\mathrm{MeIM}, \mathrm{C}_{4} \mathrm{H}_{6} \mathrm{~N}_{2}$ ), combined with chitosan gel and mixed with softwood kraft pulp to produce ZIF-8/chitosan/cellulose composite paper filters. Chitosan prevented MOF agglomeration and enhanced the compatibility between ZIF-8 and the cellulose fibers. The ZIF-8/chitosan addition did not affect the tensile index and provided antibacterial properties to the composite paper, but it decreased the evenness index used to evaluate the quality of formation and the uniformity of the paper sheets. The ZIF-8/chitosan/cellulose composite filters of $60 \mathrm{~g} / \mathrm{m}^{2}$ basis weight had $99.68 \%$ filtration efficiency for removing particles $\leq 2.5 \mu \mathrm{m}$ in diameter, compared to a $94 \%$ efficiency for untreated paper. The composite paper had an ultra-high specific surface of $139 \mathrm{~m}^{2} / \mathrm{g}$, compared to $0.77 \mathrm{~m}^{2} / \mathrm{g}$ for untreated paper. Additionally, the air permeability of the composite papers increased by more than 50\% compared to the untreated papers (Nie et al. 2020a). These results are encouraging, as filtration and breathability are generally two opposing properties of mask filters, especially for cellulose-based filters. Moreover, Nie et al. (2020a,b) state that $\mathrm{MOF} /$ chitosan gel can be added directly to the wood pulp and therefore would not require a change in paper manufacturing. Studies have also reported the use of MOFs to produce multifunctional cellulose-based filters with ultra-high filtration efficiency, adsorption properties, and antibacterial properties for the healthcare industry (Ma et al. 2018). Ma et al. (2018) produced biodegradable MOF/cellulose filters using ZIF-8, MOF-199, and AgMOFs by in-situ deposition on the cellulose matrix. The MOF/cellulose filters were compared to pure cellulose filters, all made of fibrillated softwood kraft pulp. The ZIF-8 was deposited directly to the pulp suspension diluted in distilled water, reacted in an autoclave at $75{ }^{\circ} \mathrm{C}$ for $24 \mathrm{~h}$, and freeze-dried to remove the residual solvent. Similar methods were used for the other MOFs, except that MOF-199 was deposited upon the pulp suspension diluted in composite solvents of N,N-dimethylformamide, ethanol, and water $(1: 1: 1)$ and reacted at $85^{\circ} \mathrm{C}$ for $24 \mathrm{~h}$, while $\mathrm{Ag}$-MOFs were reacted at $120{ }^{\circ} \mathrm{C}$ for $72 \mathrm{~h}$. The ZIF-8/cellulose, MOF-199/cellulose, and Ag-MOF/cellulose filters had filtration efficiencies of $98.36 \%, 98.28 \%$, and $97.34 \%$ against $0.3-\mu \mathrm{m}$ particles, respectively, while 
pure cellulose filters had only approximately $44 \%$ efficiency. However, unlike ZIF8/chitosan/cellulose composite filters (Nie et al. 2020a), ZIF-8/cellulose, MOF199/cellulose, and Ag-MOF/cellulose filters had higher pressure drops (134 Pa, $131 \mathrm{~Pa}$, and $126 \mathrm{~Pa}$, respectively) compared to pure cellulose filters (approximately $25 \mathrm{~Pa}$ ). The antibacterial activities followed the order Ag-MOF/cellulose filter > MOF-199/cellulose filter $>$ ZIF-8/cellulose filter (Ma et al. 2018). Similar results for filtration efficiency and pressure drop of ZIF-8/cellulose filters were obtained by Su et al. (2018).

\section{Quaternary ammonium and other salts}

Recently, the Indian Department of Biotechnology's Institute for Stem Cell Science and Regenerative Medicine (Bangalore, India) developed an antiviral face mask composed of cotton fibers impregnated with quaternary ammonium salts, which will be commercialized under the brand name G99+ by the Color Threads company in India. Because SARS-CoV-2 is an enveloped virus composed of a lipid membrane with negatively charged ions, it is expected that quaternary ammonium salts containing positively charged nitrogen could disrupt the virus envelope through the same principle of action as Ag ions, although they have not yet been tested against SARS-CoV-2 (Sachan 2020). Quaternary ammonium compounds are among the most studied functional groups to provide antibacterial properties to cellulosic materials (Tavakolian et al. 2020) and other biomaterials and are commercially used in the manufacture of antimicrobial textiles (e.g., cotton, polyester, and nylon) (Ristić et al. 2011), which make them a good candidate for antiviral cellulose-based filters. Sodium chloride $(\mathrm{NaCl})$ is another inorganic salt used as an antiviral agent applicable to medical face masks. Quan et al. (2017) reported the use of $\mathrm{NaCl}$ coatings to treat the middle layer of three-ply surgical masks made of polypropylene microfiber; a surfactant was also used to enhance the wetting of saline solutions on the hydrophobic surfaces of polypropylene fibers. Their results showed that $\mathrm{NaCl}$-coated filters exhibited high efficiency (approximately 85\%) against aerosols containing H1N1 influenza viruses through a salt-recrystallization-based filtration system, which completely inactivated different types of adsorbed influenza viruses. Moreover, the $\mathrm{NaCl}$ coating exhibited stability at high temperature and humidity, suggesting safe use and long-term storage, in addition to being simpler and less expensive than other antiviral technologies. Sodium chloride coatings on surgical face masks are also currently being investigated at the University of Alberta in Canada (Bogart 2020).

\section{$N$-halamines}

$\mathrm{N}$-halamines are a group of organic synthetic polymeric compounds and can be used as effective antimicrobial, antibacterial, and antiviral agents in protective masks (Ren et al. 2018; Huang et al. 2019). Huang et al. (2019) produced polyacrylonitrile (PAN)nanofiber membranes with the addition of $5 \%$ of a type of N-halamine (1-chloro-2,2,5,5tetramethyl-4-imidazolidinone, $\mathrm{MC}$ ) by electrospinning for potential applications in protective masks. Their results showed that PAN/MC membranes have excellent antibacterial efficiency but a $20 \%$ decreased air permeability compared to untreated PAN membranes, although both reached breathability requirements. Ren et al. (2018) studied the antiviral activities of the nonwoven fabric of a commercial N95 respirator coated with MC concentrations of $0.1 \%$ to $1 \%$ and showed that higher MC concentrations considerably reduced the presence of the avian influenza virus in the filter and completely inactivated the viruses by disrupting their RNA. According to Tavakolian et al. (2020), the cellulose surface can be easily grafted with $\mathrm{N}$-halamine due to the abundance of hydroxyl groups, 
thus developing durable antimicrobial properties. For instance, an N-halamine precursor (polyethylenimine, PEI) was grafted onto dialdehyde cellulose membranes, followed by chlorination, to prepare antibacterial $\mathrm{N}$-halamine/cellulose membranes for wound dressing materials. The N-halamine/aldehyde-cellulose membrane completely inactivated bacterial pathogens within $5 \mathrm{~min}$ even after $15 \mathrm{~d}$ of storage and exhibited an increase of approximately $38 \%$ in elongation at break and a slight decrease in tensile strength (105 $\mathrm{MPa}$ ) compared to the ungrafted membrane (112.8 MPa) (Zhang et al. 2019b). N-halamine compounds have long-term stability and low environmental impact (Huang et al. 2019), are safe for humans, and can be grafted onto other antimicrobial materials such as chitosan.

\section{PHMB}

Polyhexamethylene biguanide is another polymer that is widely used as a biocide in numerous applications, including wound dressing, hand washes, personal care products, finishing for textiles (mainly for cellulose-based textiles) (Ristić et al. 2011), face masks, medical devices, and surgical instruments (Schorr et al. 2007). A Kimberly-Clark patent describes an antimicrobial composition containing a mixture of PHMB hydrochloride and a synergistic coactive agent (e.g., another biguanide, QACs, or natural agents, among others) that can be coated on the outer layer of face masks made of cellulose-based or synthetic polymeric nonwoven sheets, polymeric films, or a combination thereof. Polyhexamethylene biguanide hydrochloride is a cationic biguanide that attracts and disrupts the negatively charged membranes of most microorganisms, and the damage to the membrane increases with the degree of polymerization of the biguanide (Schorr et al. 2007). Polyhexamethylene biguanide is characterized by low toxicity and is skin-friendly, non-mutagenic, non-carcinogenic, showing oral tolerance (Timofeeva and Kleshcheva 2011), and odorless to humans, which are important characteristics for face masks (Schorr et al. 2007).

\section{Carbon materials}

Graphene is a carbon-based 2D nanostructured material with antibacterial and potentially antiviral properties that can also be used as a superhydrophobic agent for disposable surgical masks, as pointed out in a recent study (Zhong et al. 2020). The authors proposed a method for functionalizing commercial surgical masks made from polypropylene fibers with self-cleaning and photothermal properties using a porous graphene coating. Functionalized graphene masks were produced from a polyimide precursor film through a fourth-generation laser technique that was used to transfer the hydrophobic graphene layer. These masks were demonstrated to be efficient in bouncing particles and could be reused after solar sterilization, because the SARS-CoV-2 spike protein, which is used as a means of infection, is sensitive to temperature. The photothermal performance of graphene-coated versus pristine masks was measured by absorbance, which was maximal for graphene-coated masks while being relatively low for pristine ones, especially in the visible and UV portions of the spectrum. Variations of the surface temperatures of the masks over time were measured by an infrared camera. While the surface temperature of the classical surgical masks remained at approximately $45^{\circ} \mathrm{C}$ after 5 min of solar illumination, the graphene-coated surface reached a temperature of $70{ }^{\circ} \mathrm{C}$ in $40 \mathrm{~s}$ and maintained a temperature of $80{ }^{\circ} \mathrm{C}$ after $100 \mathrm{~s}$ of illumination, a temperature sufficiently high to inactivate viruses (Zhong et al. 2020). Huang et al. (2020) report that the antibacterial efficiency of laser-induced graphene masks is improved to approximately $81 \%$ and could be increased to $99.998 \%$ within 10 min under sunlight, while in common 
face masks $90 \%$ of bacteria remain alive after $8 \mathrm{~h}$, creating a biohazard and environmental concerns when they are improperly used or discarded. Some graphene face masks have recently appeared on the international market. United Kingdom-based PlanarTECH, for example, has developed a washable and reusable face mask coated with graphene and other carbon nanomaterials (Graphene Catalog 2020). Additionally, a three-layer disposable face mask from Transon features an antibacterial protective inner layer of biomass graphene composite (Transon 2019). Regarding cellulosic materials, a study reports the benefits of graphene oxide (GO) and Ag NPs added to dissolved cellulose to improve the physical and antibacterial properties of nanocomposite membranes (Chook et al. 2014). Graphene oxide caused the immobilization of Ag NPs in solution, preventing their aggregation and improving their colloidal stability, which resulted in a large specific surface area, thus increasing the antibacterial functionality of the nanocomposite membrane. Chen et al. (2016b) state that the most important advantage of GO / Ag NP composite is the Ag NPs' immobilization on the GO sheets, which increases material compatibility and reduces environmental impacts associated with the release of free Ag NPs. Moreover, GO / Ag NP composites have antiviral potential against enveloped and non-enveloped virusesenveloped feline coronavirus (FCoV) and bursal disease virus (IBDV), respectively- as shown by Chen et al. (2016b). They found that GO / Ag NP sheets exhibited greater virus inhibition than GO sheets alone. The latter had viral inhibition against FCoV but not against non-enveloped virus.

\section{CONCLUSIONS}

The current review provides an overview of the features of commercial N95 respirators and medical face masks, the desirable characteristics of cellulose and nanocellulose materials for the manufacture of disposable face masks, and the recent advancements in antimicrobial (nano)materials to produce functional cellulose-based filters. The currently produced commercial masks, although generally made of petroleumbased synthetic fibers, offer high filtration efficiency against harmful particles, including viruses and bacteria, and low pressure drop to allow breathability and provide comfort to the wearer. However, few commercial N95 and medical face masks currently provide antiviral properties, increasing the risks of cross-contamination since the contaminated mask may become a passive transmission vector and raising environmental concerns for their disposal after use. These concerns are particularly important for SARS-CoV-2, which is a highly contagious pathogen and able to survive for longer periods on the surface of different materials. Therefore, the challenges related to the manufacture of biodegradable cellulose-based masks are to develop filters capable of providing high filtration efficiency and low pressure drop similar to those found in commercial masks, and antimicrobial functionalities to increase protection against viruses. The targeted cellulose-based filter can be designed by adjusting different blends of softwood/hardwood chemical pulps, as coarse softwood pulp fibers offer bulk, strength, and air permeability, while hardwood pulp fibers improve filtration efficiency. Additionally, the high specific surface and versatility of fibrillated cellulose materials could improve the mechanical strength and enable the capture of submicron particles by filter media, thus permitting the adjustment of filter thickness to maintain breathability. Moreover, nanocelluloses can increase the functionality of the filter and allow for the design of more efficient functional cellulosebased composite filters. 
Among the principal antimicrobial technologies applied to masks and compatible with cellulose due to similarities of their structures, chitosan-based (nano)composites appear to be among the most promising. Many chitosan derivates are commercially available and can be combined with many other antiviral agents to form composite structures capable of being incorporated into papermaking processes. Chitosan is ecofriendly, renewable, biodegradable, non-toxic, biocompatible, and antibacterial. Chitosan also enhances the cellulose affinity with antimicrobial agents and acts as a matrix that increases the dispersion and functionalities of other antiviral/antibacterial agents such as Ag NPs and MOFs. Ideally, cellulose-based masks must present antimicrobial properties in the outer and inner layers to prevent pathogenic microorganisms from the environment from reaching the wearer and vice versa.

\section{ACKNOWLEDGMENTS}

The authors acknowledge the support of the Natural Sciences and Engineering Research Council of Canada (NSERC) by the NSERC Alliance COVID-19 grant (No. ALLRP 554160-20, grantee Alexis Achim).

\section{REFERENCES CITED}

42 CFR Part 84 (1995). “Approval of respiratory protective devices,” Code of Federal Regulations, U.S. Government Printing Office, Office of the Federal Register, Washington, DC, USA.

Ahmad, I., Kamal, T., Khan, S. B., and Asiri, A. M. (2016). "An efficient and easily retrievable dip catalyst based on silver nanoparticles/chitosan-coated cellulose filter paper," Cellulose 23, 3577-3588. DOI: 10.1007/s10570-016-1053-4

Alavi, M. (2019). "Modifications of microcrystalline cellulose (MCC), nanofibrillated cellulose (NFC), and nanocrystalline cellulose (NCC) for antimicrobial and wound healing applications," e-Polymers 19(1), 103-119. DOI: 10.1515/epoly-2019-0013

Alexandrescu, L., Syverud, K., Gatti, A., and Chinga-Carrasco, G. (2013). "Cytotoxicity tests of cellulose nanofibril-based structures," Cellulose 20, 1765-1775. DOI: 10.1007/s10570-013-9948-9

Alexandrescu, L., Syverud, K., Nicosia, A. Santachiara, G., Fabrizi, A., and Belosi, F. (2016). "Airborne nanoparticles filtration by means of cellulose nanofibril based materials," Journal of Biomaterials and Nanobiotechnology 7(1), 29-36. DOI: 10.4236/jbnb.2016.71004

American Forest \& Paper Association (2019). "Pulp," (https://www.afandpa.org/ourproducts/pulp), Accessed 27 October 2020.

ASTM D737-18 (2018). "Standard test method for air permeability of textile fabrics," ASTM International, West Conshohocken, PA, USA.

ASTM F1862/F1862M-17 (2017). "Standard test method for resistance of medical face masks to penetration by synthetic blood (horizontal projection of fixed volume at a known velocity)," ASTM International, West Conshohocken, PA, USA.

ASTM F2100-19e1 (2019). "Standard specification for performance of materials used in medical face masks," ASTM International, West Conshohocken, PA, USA. 
ASTM F2101-19 (2019). "Standard test method for evaluating the bacterial filtration efficiency (BFE) of medical face mask materials, using a biological aerosol of Staphylococcus aureus," ASTM International, West Conshohocken, PA, USA.

ASTM F2299/F2299M-03 (2017). "Standard test method for determining the initial efficiency of materials used in medical face masks to penetration by particulates using latex spheres," ASTM International, West Conshohocken, PA, USA.

Auty, D., Moore, J., Achim, A., Lyon, A., Mochan, S., and Gardiner, B. (2018). "Effects of early respacing on the density and microfibril angle of Sitka spruce wood," Forestry 91(3), 307-319. DOI: 10.1093/forestry/cpx004

Bajpai, P. (2017a). Pulp and Paper Industry: Chemical Recovery, Elsevier, Amsterdam, The Netherlands.

Bajpai, P. (2017b). Pulp and Paper Industry: Nanotechnology in Forest Industry, Elsevier, Amsterdam, The Netherlands.

Ball, V. (2018). "Polydopamine nanomaterials: Recent advances in synthesis methods and applications," Frontiers in Bioengineering and Biotechnology 6. DOI: 10.3389/fbioe.2018.00109

Beck-Candanedo, S., Roman, M., and Gray, D. G. (2005). "Effect of reaction conditions on the properties and behavior of wood cellulose nanocrystal suspensions," Biomacromolecules 6(2), 1048-1054. DOI: 10.1021/bm049300p

Bernier, C., Briand, S., Cortin, V., Ouhoummane, N., and Pelletier, A. (2020). COVID19: Évaluation des Options de Désinfection des Appareils de Protection Respiratoire N95 dans le Contexte de la Pandémie [COVID-19: Evaluation of Disinfection Options for N95 Filtering Facepiece Respirators in the Context of the Pandemic] (Publication No. 2971), Institut National de Santé Publique du Québec, Quebec City, QC, Canada.

Berger, M. (2020). "What is a MOF (metal-organic framework)?," (https://www.nanowerk.com/mof-metal-organic-framework.php), Accessed 26 August 2020.

Bharimalla, A. K., Deshmukh, S. P., Patil, P. G., and Vigneshwaran, N. (2015). "Energy efficient manufacturing of nanocellulose by chemo- and bio-mechanical processes: A review," World Journal of Nano Science and Engineering 5(4), 204-212. DOI: 10.4236/wjnse.2015.54021

Bogart, N. (2020). "A salt-coated mask that kills viruses? Alberta researchers working on it," (https://www.ctvnews.ca/health/a-salt-coated-mask-that-kills-viruses-albertaresearchers-working-on-it-1.4798138), Accessed 03 July 2020.

Borkow, G., Zhou, S. S., Page, T., and Gabbay, J. (2010). “A novel anti-influenza copper oxide containing respiratory face mask," PLoS One 5(6). DOI: 10.1371/journal.pone.0011295

Bright, K. R., Sicairos-Ruelas, E. E., Gundy, P. M., and Gerba, C. P. (2009). "Assessment of the antiviral properties of zeolites containing metal ions," Food and Environmental Virology 1, 37-41. DOI: 10.1007/s12560-008-9006-1

Business Examiner (2020). "Harmac Pacific helps to meet demands of medical masks," (https://businessexaminer.ca/victoria-articles/item/harmac-pacific-helps-to-meetdemands-of-medical-masks/), Accessed 07 January 2021.

Catel-Ferreira, M., Tnani, H., Hellio, C., Cosette, P., and Lebrun, L. (2015). “Antiviral effects of polyphenols: Development of bio-based cleaning wipes and filters," Journal of Virological Methods 212, 1-7. DOI: 10.1016/j.jviromet.2014.10.008 
Chen, C., Duan, C., Li, J., Liu, Y., Ma, X., Zheng, L., Stavik, J., and Ni, Y. (2016a). "Cellulose (dissolving pulp) manufacturing processes and properties: A mini-review," BioResources 11(2), 5553-5564. DOI: 10.15376/biores.11.2.Chen

Chen, Y.-N., Hsueh, Y.-H., Hsieh, C.-T., Tzou, D.-Y., and Chang, P.-L. (2016b). "Antiviral activity of graphene-silver nanocomposites against non-enveloped and enveloped viruses," International Journal of Environmental Research and Public Health 13(4). DOI: 10.3390/ijerph13040430

Chook, S. W., Chia, C. H., Zakaria, S., Ayob, M. K., Huang, N. M., Neoh, H. M., He, M., Zhang, L., and Jamal, R. (2014). "A graphene oxide facilitated a highly porous and effective antibacterial regenerated cellulose membrane containing stabilized silver nanoparticles," Cellulose 21, 4261-4270. DOI: 10.1007/s10570-014-0395-z

Chua, M. H., Cheng, W., Goh, S. S., Kong, J., Li, B., Lim, J. Y. C., Mao, L., Wang, S., Xue, K., Yang, L., et al. (2020). "Face masks in the new COVID-19 normal: Materials, testing, and perspectives," Research 2020. DOI: 10.34133/2020/7286735

Ciuffreda, S., Picotti, C., and Pescio, P. (2020). Medical Face Masks on the Market: Review of Materials, Characteristics and Performed Tests, Eurofins Medical Device Testing, Milan, Italy.

Courchene, C. E., Peter, G. F., and Litvay, J. (2006). "Cellulose microfibril angle as a determinant of paper strength and hygroexpansivity in Pinus taeda L.," Wood and Fiber Science 38(1), 112-120.

Davison, A. M. (2012). "Pathogen inactivation and filtration efficacy of a new antimicrobial and anti-viral surgical facemask and N95 against dentistry-associated microorganisms," International Dentistry - Australasian Edition 7(1), 36-42.

Dimic-Misic, K., Maloney, T., and Gane, P. (2018). "Effect of fibril length, aspect ratio and surface charge on ultralow shear-induced structuring in micro and nanofibrillated cellulose aqueous suspensions," Cellulose 25, 117-136. DOI: 10.1007/s10570-0171584-3

Drolet, F., Ricard, M. A., Bouchard-Aubin, C., Pagé, N., and Dorris, G. (2017). "Filter media comprising cellulose filaments," World Patent No. WO 2017/008171 A1.

Emam, H. E. (2019). "Generic strategies for functionalization of cellulosic textiles with metal salts," Cellulose 26, 1431-1447. DOI: 10.1007/s10570-018-2185-5

Fairbank, M. (2020). "Filaments de cellulose - du laboratoire à la réalité [Cellulose filaments - From the laboratory to reality]," (https://www.lemaitrepapetier.ca/blogues/martin-fairbank/filaments-de-cellulose$\%$ E2\%80\%93-du-laboratoire-\%C3\%A0-la-r\%C3\%A9alit\%C3\%A9.html), Accessed 05 August 2020.

Furman, Jr., G. S., Frette, G., Koenig, F., and Maurer, T. (2013). "Debonder and softener compositions," U. S. Patent No. 8518214 B2.

Galdiero, S., Falanga, A., Vitiello, M., Cantisani, M., Marra, V., and Galdiero, M. (2011). "Silver nanoparticles as potential antiviral agents," Molecules 16(10), 8894-8918. DOI: $10.3390 /$ molecules16108894

Gargoubi, S., Saghrouni, F., Chevallier, P., Tolouei, R., Boudokhane, C., Ladhari, N., and Mantovani, D. (2020). "Polydopamine-modified interface improves the immobilization of natural bioactive-dye onto textile and enhances antifungal activity," Biointerphases 15(4). DOI: 10.1116/6.0000295

Ghosh, S. (2014). "Composite nonwovens in medical applications," in: Composite Nonwoven Materials: Structure, Properties and Applications, D. Das and B. Pourdeyhimi 
(eds.), Woodhead Publishing, Cambridge, UK, pp. 211-224. DOI: $10.1533 / 9780857097750.211$

Graphene Catalog (2020). "Graphene face masks," (https://catalog.grapheneinfo.com/graphene-masks), Accessed 15 September 2020.

Hahn, T., Bossog, L., Hager, T., Wunderlich, W., Breier, R., Stegmaier, T., and Zibek, S. (2020). "Chitosan application in textile processing and fabric coating," in: Chitin and Chitosan: Properties and Applications, L. A. M. van den Broek and C. G. Boeriu (eds.), John Wiley \& Sons Ltd., Chichester, UK, pp. 395-428. DOI: 10.1002/9781119450467.ch16

Hamad, W. Y., Miao, C., and Beck, S. (2019). "Growing the bioeconomy: Advances in the development of applications for cellulose filaments and nanocrystals," Industrial Biotechnology 15(3), 133-137. DOI: 10.1089/ind.2019.29172.qyh

Hamann, J. (2020). "Un coton du futur pour les chaussettes et les masques? [A cotton of the future for socks and masks?]," (https://nouvelles.ulaval.ca/recherche/un-coton-dufutur-pour-les-chaussettes-et-les-masques-bf325e8fdfd22bd5522d05414eacb8e9), Accessed 17 September 2020.

He, M., Chen, H., Zhang, X., Wang, C., Xu, C., Xue, Y., Wang, J., Zhou, P., and Zhao, Q. (2018). "Construction of novel cellulose/chitosan composite hydrogels and films and their applications," Cellulose 25, 1987-1996. DOI: 10.1007/s10570-018-1683-9

He, X., Reponen, T., McKay, R., and Grinshpun, S. A. (2014). "How does breathing frequency affect the performance of an N95 filtering facepiece respirator and a surgical mask against surrogates of viral particles?," Journal of Occupational and Environmental Hygiene 11(3), 178-185. DOI: 10.1080/15459624.2013.848037

He, X., Reponen, T., McKay, R. T., and Grinshpun, S. A. (2013). "Effect of particle size on the performance of an N95 filtering facepiece respirator and a surgical mask at various breathing conditions," Aerosol Science and Technology 47(11), 1180-1187. DOI: 10.1080/02786826.2013.829209

Hendrikx, R. (2019). “Air filtration: Advantages of PTFE materials,” (https://cleanroomtechnology.com/news/article_page/Air_filtration_Advantages_of_P TFE_materials/153455), Accessed 26 October 2020.

Henneberry, B. (2020). "How to make N95 masks," (https://www.thomasnet.com/articles/plant-facility-equipment/how-to-make-n95masks/), Accessed 20 August 2020.

Hiremath, N., and Bhat, G. (2015). "Melt blown polymeric nanofibers for medical applications - An overview," Nanoscience \& Technology: Open Access 2(1), 1-9. DOI: $10.15226 / 2374-8141 / 2 / 1 / 00125$

Huang, C., Liu, Y., Li, Z., Li, R., Ren, X., and Huang, T.-S. (2019). "N-halamine antibacterial nanofibrous mats based on polyacrylonitrile and $\mathrm{N}$-halamine for protective face masks," Journal of Engineered Fibers and Fabrics 14, 1-8. DOI: $10.1177 / 1558925019843222$

Huang, L., Xu, S., Wang, Z., Xue, K., Su, J., Song, Y., Chen, S., Zhu, C., Tang, B. Z., and Ye, R. (2020). "Self-reporting and photothermally enhanced rapid bacterial killing on a laser-induced graphene mask," ACS Nano 14(9), 12045-12053. DOI: 10.1021/acsnano.0c05330

Hutten, I. M. (2016). Handbook of Nonwoven Filter Media, Butterworth-Heinemann, Oxford, UK. 
Imani, R., Talaiepour, M., Dutta, J., Ghobadinezhad, M. R., Hemmasi, A. H., and Nazhad, M. M. (2011). "Production of antibacterial filter paper from wood cellulose," BioResources 6(1), 891-900. DOI: 10.15376/biores.6.1.891-900

Inovenso Technology (2018). "N95/N99 nanofiber face mask," (https://www.inovenso.com/nanofiber-facemask/nanofiber-facemask/), Accessed 14 August 2020.

Institute of Medicine (2006). "Characteristics of respirators and medical masks," in: Reusability of Facemasks during an Influenza Pandemic: Facing the Flu, The National Academies Press, Washington, DC, USA, pp. 22-41. DOI: 10.17226/11637

Jordan, L., Daniels, R. F., Clark, A., and He, R. (2005). "Multilevel nonlinear mixedeffects models for the modeling of earlywood and latewood microfibril angle," Forest Science 51(4), 357-371.

Khalil, H. P. S. A., Davoudpour, Y., Islam, M. N., Mustapha, A., Sudesh, K., Dungani, R., and Jawaid, M. (2014). "Production and modification of nanofibrillated cellulose using various mechanical processes: A review," Carbohydrate Polymers 99, 649-665. DOI: 10.1016/j.carbpol.2013.08.069

Klemm, D., Kramer, F., Moritz, S., Lindström, T., Ankerfors, M., Gray, D., and Dorris, A. (2011). "Nanocelluloses: A new family of nature-based materials," Angewandte Chemie International Edition 50(24), 5438-5466. DOI: 10.1002/anie.201001273

Kruger Biomaterials (2018). "Biomaterials," (https://biomaterials.kruger.com/), Accessed 29 June 2020.

Kucharska, M., Sikora, M., Brzoza-Malczewska, K., and Owczarek, M. (2020). "Antimicrobial properties of chitin and chitosan," in: Chitin and Chitosan: Properties and Applications, L. A. M. van den Broek and C. G. Boeriu (eds.), John Wiley \& Sons Ltd., Chichester, UK, pp. 169-188. DOI: 10.1002/9781119450467.ch7

Leung, N. H. L., Chu, D. K. W., Shiu, E. Y. C., Chan, K.-H., McDevitt, J. J., Hau, B. J. P., Yen, H.-L., Li, Y., Ip, D. K. M., Peiris, J. S. M., et al. (2020). "Respiratory virus shedding in exhaled breath and efficacy of face masks," Nature Medicine 26, 676680. DOI: 10.1038/s41591-020-0843-2

Lim, H. (2010). "A review of spun bond process," Journal of Textile and Apparel, Technology and Management 6(3), 1-13.

Lin, L.-T, Hsu, W.-C., and Lin, C.-C. (2014). "Antiviral natural products and herbal medicines," Journal of Traditional and Complementary Medicine 4(1), 24-35. DOI: $10.4103 / 2225-4110.124335$

Ling, Y., Luo, Y., Luo, J., Wang, X., and Sun, R. (2013). "Novel antibacterial paper based on quaternized carboxymethyl chitosan/organic montmorillonite/Ag NP nanocomposites," Industrial Crops and Products 51, 470-479. DOI: 10.1016/j.indcrop.2013.09.040

Long, J., Tang, M., Liang, Y., and Hu, J. (2018). "Preparation of fibrillated cellulose nanofiber from lyocell fiber and its application in air filtration," Materials 11(8). DOI: $10.3390 / \mathrm{ma} 11081313$

Loutfy, S. A., Elberry, M. H., Farroh, K. Y., Mohamed, H. T., Mohamed, A. A., Mohamed, E. B., Faraag, A. H. I, and Mousa, S. A. (2020). "Antiviral activity of chitosan nanoparticles encapsulating curcumin against hepatitis $C$ virus genotype $4 a$ in human hepatoma cell lines," International Journal of Nanomedicine 15, 26992715. DOI: $10.2147 /$ IJN.S241702

Lu, Z., Su, Z., Song, S., Zhao, Y., Ma, S., and Zhang, M. (2018). “Toward highperformance fibrillated cellulose-based air filter via constructing spider-web-like 
structure with the aid of TBA during freeze-drying process," Cellulose 25, 619-629.

DOI: $10.1007 / \mathrm{s} 10570-017-1561-\mathrm{X}$

M-Chitosan (2020). "Products," (https://intl.m-chitosan.com/products/), Accessed 28 October 2020.

Ma, S., Zhang, M., Nie, J., Yang, B., Song, S., and Lu, P. (2018). "Multifunctional cellulose-based air filters with high loadings of metal-organic frameworks prepared by in situ growth method for gas adsorption and antibacterial applications," Cellulose 25, 5999-6010. DOI: 10.1007/s10570-018-1982-1

Macdonald, E., and Hubert, J. (2002). "A review of the effects of silviculture on timber quality of Sitka spruce," Forestry: An International Journal of Forest Research 75(2), 107-138. DOI: 10.1093/forestry/75.2.107

Malkan, S. R., and Wadsworth, L. C. (1993). "Polymer-laid systems," in: Nonwovens: Theory, Process, Performance, and Testing, A. F. Turbak (ed.), TAPPI Press, Atlanta, GA, USA, pp. 171-192.

Mao, J., Grgic, B., Finlay, W. H., Kadla, J. F., and Kerekes, R. J. (2008). "Wood pulp based filters for removal of sub-micrometer aerosol particles," Nordic Pulp \& Paper Research Journal 23(4), 420-425. DOI: 10.3183/npprj-2008-23-04-p420-425

Mao, N. (2016). "Nonwoven fabric filters," in: Advances in Technical Nonwovens, G. Kellie (ed.), Woodhead Publishing, Duxford, UK. DOI: 10.1016/B978-0-08-100575$0.00010-3$

Medline (2020). "Face masks, eyewear and N95 respirators: Every protection level and preference," (https://www.medline.com/media/catalog/Docs/MKT/LITe19034_ BRO_Surgical\%20Face\%20Masks_19.pdf), Accessed 27 October 2020.

Milewska, A., Ciejka, J., Kaminski, K., Karewicz, A., Bielska, D., Zeglen, S., Karolak, W., Nowakowska, M., Potempa, J., Bosch, B. J., et al. (2013). "Novel polymeric inhibitors of HCoV-NL63," Antiviral Research 97(2), 112-121. DOI: 10.1016/j.antiviral.2012.11.006

Miller, J. (2018). "2018- Cellulose nanomaterials production update: Summer, 2018," (https://www.tappinano.org/media/1266/2018-cellulose-nanomaterials-productionupdate.pdf), Accessed 25 January 2021.

Moghadamtousi, S. Z., Kadir, H. A., Hassandarvish, P., Tajik, H., Abubakar, S., and Zandi, K. (2014). "A review on antibacterial, antiviral, and antifungal activity of curcumin," BioMed Research International 2014. DOI: 10.1155/2014/186864

Mori, Y., Ono, T., Miyahira, Y., Nguyen, V. Q., Matsui, T., and Ishihara, M. (2013). "Antiviral activity of silver nanoparticle/chitosan composites against H1N1 influenza A virus," Nanoscale Research Letters 8. DOI: 10.1186/1556-276X-8-93

Mostofi, R., Wang, B., Haghighat, F., Bahloul, A., and Jaime, L. (2010). "Performance of mechanical filters and respirators for capturing nanoparticles - Limitations and future direction," Industrial Health 48(3), 296-304. DOI: 10.2486/indhealth.48.296

Mukhopadhyay, A. (2014). "Composite nonwovens in filters: Applications," in: Composite Non-woven Materials: Structure, Properties and Applications, D. Das and B. Pourdeyhimi (eds.), Woodhead Publishing, Cambridge, UK, pp. 164-210. DOI: 10.1533/9780857097750.164

Nelson Labs (2019). "Protective barriers \& material performance," (https://www.nelsonlabs.com/find-a-test/medical-devices/protective-barriers-materialperformance/), Accessed 09 July 2020.

Nexera Medical (2020). “Antimicrobial technology,” (http://www.nexeramed.com/cfiles/ products_antimicrobial.php), Accessed 31 August 2020. 
Nie, J., Song, S., and Liang, J. (2020b). "Gels serving as carriers for functional fillers and facilitating novel composite paper production," BioResources 15(4), 7313-7314.

Nie, J., Xie, H., Zhang, M., Liang, J., Nie, S., and Han, W. (2020a). "Effective and facile fabrication of MOFs/cellulose composite paper for air hazards removal by virtue of in situ synthesis of MOFs/chitosan hydrogel," Carbohydrate Polymers 250. DOI: 10.1016/j.carbpol.2020.116955

NIOSH (2014). "NIOSH guide to the selection and use of particulate respirators," The National Institute for Occupational Safety and Health, (https://www.cdc.gov/niosh/docs/96-101/default.html), Accessed 02 July 2020.

NPPTL (2020). "Approved particulate filtering facepiece respirators," The National Personal Protective Technology Laboratory, (https://www.cdc.gov/niosh/npptl/topics/ respirators/disp_part/default.html), Accessed 30 June 2020.

Osman, E. (2020). "Nanofinished medical textiles and their potential impact to health and environment," in: Nanoparticles and Their Biomedical Applications, A. K. Shukla (ed.), Springer Nature Singapore, Singapore, pp. 127-145. DOI: 10.1007/978-981-150391-7_5

Pan, Z., Liang, Y., Tang, M., Sun, Z., Hu, J., and Wang, J. (2019). "Simulation of performance of fibrous filter media composed of cellulose and synthetic fibers," Cellulose 26, 7051-7065. DOI: 10.1007/s10570-019-02605-8

Polymer Properties Database (2015). "Regenerated cellulose fibers (viscose rayon)," (https://polymerdatabase.com/Fibers/Rayon.html), Accessed 17 July 2020.

Prather, K. A., Marr, L. C., Schooley, R. T., McDiarmid, M. A., Wilson, M. E., and Milton, D. K. (2020). “Airborne transmission of SARS-CoV-2," Science 370(6514), 303-304. DOI: 10.1126/science.abf0521

Public Works and Government Services Canada (2020). "Specifications for COVID-19 products," (https://buyandsell.gc.ca/specifications-for-COVID-19-products\#200), Accessed 22 November 2020.

Qin, Y. (2016). Medical Textile Materials, Woodhead Publishing, Cambridge, UK.

Quan, F.-S., Rubino, I., Lee, S.-H., Koch, B., and Choi, H.-J. (2017). "Universal and reusable virus deactivation system for respiratory protection," Scientific Reports 7. DOI: $10.1038 /$ srep39956

Ramirez, J. A. (2015). Evaluation of Particle Penetration and Breathing Resistance of N95 Filtering Face-piece Respirators and Uncertified Dust Masks, Ph.D. Thesis, The University of Iowa, Iowa City, IA, USA.

Ren, T., Dormitorio, T. V., Qiao, M., Huang, T.-S., and Weese, J. (2018). "N-halamine incorporated nonwoven fabrics for use against avian influenza virus," Veterinary Microbiology 218, 78-83. DOI: 10.1016/j.vetmic.2018.03.032

Rengasamy, S., Miller, A., and Eimer, B. C. (2011). "Evaluation of the filtration performance of NIOSH-approved N95 filtering facepiece respirators by photometric and number-based test methods," Journal of Occupational and Environmental Hygiene 8(1), 23-30. DOI: 10.1080/15459624.2010.515556

Rengasamy, S., Miller, A., Vo, E., and Eimer, B. C. (2013). "Filter performance degradation of electrostatic N95 and P100 filtering facepiece respirators by dioctyl phthalate aerosol loading," Journal of Engineered Fibers and Fabrics 8(3), 62-69. DOI: $10.1177 / 155892501300800307$

RespoKare (2017). "RespoKare ${ }^{\circledR}$ anti-viral mask," (https://respokare.com/), Accessed 31 August 2020. 
Ristić, T., Zemljič, L. F., Novak, M., Kunčič, M. K., Sonjak, S., Cimerman, N. G., and Strnad, S. (2011). "Antimicrobial efficiency of functionalized cellulose fibres as potential medical textiles," in: Science against Microbial Pathogens: Communicating Current Research and Technological Advances," A. Méndez-Vilas (ed.), Formatex Research Center, Badajoz, Spain, pp. 36-51.

Rogister, Y., and Croes, M. (2013). "Surgical mask performance: European standard requirements examined," AMH Disposable Healthcare Products January 2013, 64-67.

Rom, M., Dutkiewicz, J., Fryczkowska, B., and Fryczkowski, R. (2007). "The hydrophobisation of cellulose pulp," Fibres \& Textiles in Eastern Europe 15(5-6), 141-144.

Rowell, R. M., Pettersen, R., Han, J. S., Rowell, J. S., and Tshabalala, M. A. (2005). "Cell wall chemistry," in: Handbook of Wood Chemistry and Wood Composites, R. M. Rowell (ed.), CRC Press, Boca Raton, FL, USA.

Sachan, D. (2020). "Designing a better face mask," Chemical \& Engineering News 98(31), 18-21. DOI: 10.1021/cen-09831-feature1

Schorr, P. A., Yahiaoui, A., Hoffman, D. R., Koenig, D. W., Spencer, A. S., and Dobson, A. G. (2007). "Antimicrobial substrates," World Patent No. WO 2007/027871 A2.

Schweingruber, F. H. (2007). Wood Structure and Environment, Springer-Verlag, Berlin, Germany. DOI: 10.1007/978-3-540-48548-3

Shimasaki, N., Okaue, A., Morimoto, M., Uchida, Y., Koshiba, T., Tsunoda, K., Arakawa, S., and Shinohara, K. (2020). "A multifaceted evaluation on the penetration resistance of protective clothing fabrics against viral liquid drops without pressure," Biocontrol Science 25(1), 9-16. DOI: 10.4265/bio.25.9

Sim, K., and Youn, H. J. (2016). "Preparation of porous sheets with high mechanical strength by the addition of cellulose nanofibrils," Cellulose 23, 1383-1392. DOI: $10.1007 / \mathrm{s} 10570-016-0865-6$

Solenis (2015). "Tissue technology," (https://solenis.com/application/files/4614/ 3767/9708/TissueTechnology.pdf), Accessed 25 January 2021.

Solvay (2020). "Polymers for nonwovens used in N95, FFP2, FFP3, and surgical masks," (https://www.solvay.com/en/chemical-categories/specialty-polymers/healthcare/ medical-equipment-emergency-production/n95-masks), Accessed 08 July 2020.

Stevanovic, T., and Koumba Yoya, G. (2019). "Organosolv process for the extraction of highly pure lignin and products comprising the same," U. S. Patent Application No. 2019/0062359 A1.

Su, Z., Zhang, M., Lu, Z., Song, S., Zhao, Y., and Hao, Y. (2018). "Functionalization of cellulose fiber by in situ growth of zeolitic imidazolate framework-8 (ZIF-8) nanocrystals for preparing a cellulose-based air filter with gas adsorption ability," Cellulose 25, 1997-2008. DOI: 10.1007/s10570-018-1696-4

Tavakolian, M., Jafari, S. M., and van de Ven, T. G. M. (2020). “A review on surface-functionalized cellulosic nanostructures as biocompatible antibacterial materials," Nano-Micro Letters 12. DOI: 10.1007/s40820-020-0408-4

Timofeeva, L., and Kleshcheva, N. (2011). "Antimicrobial polymers: Mechanism of action, factors of activity, and applications," Applied Microbiology and Biotechnology 89(3), 475-492. DOI: 10.1007/s00253-010-2920-9

Tong, H. W., Kwok, S. K. C., and Kwok, H. C. (2016). "Protective masks with coating comprising different electrospun fibers interweaved with each other, formulations forming the same, and method of producing thereof," U. S. Patent Application No. 2016/0174631 A1. 
Trache, D., Tarchoun, A. F., Derradji, M., Hamidon, T. S., Masruchin, N., Brosse, N., and Hussin, M. H. (2020). "Nanocellulose: From fundamentals to advanced applications," Frontiers in Chemistry 8. DOI: 10.3389/fchem.2020.00392

Transon (2019). "Certified 3 ply earloop biomass graphene anti-bacteria disposable face mask with meltblown nonwoven fabric," (https://www.transoncnc.com/certified-3ply-earloop-biomass-graphene-anti-bacteria-disposable-face-mask-with-meltblownnonwoven-fabric), Accessed 05 October 2020.

Tuukkanen, S., and Rajala, S. (2018). "Nanocellulose as a piezoelectric material," in: Piezoelectricity: Organic and Inorganic Materials and Applications, S. G. Vassiliadis and D. Matsouka (eds.), IntechOpen, London, UK. DOI: 10.5772/intechopen.77025

van de Ven, T. G. M., and Sheikhi, A. (2016). "Hairy cellulose nanocrystalloids: A novel class of nanocellulose," Nanoscale 8(33), 15101-15114. DOI: 10.1039/c6nr01570k

Vaughn, E., and Ramachandran, G. (2002). "Fiberglass vs. synthetic air filtration media," International Nonwovens Journal 11(3), 41-51. DOI: 10.1177/1558925002OS01100309

Vaz, J. M., Michel, E. C., Chevallier, P., Beppu, M. M., and Mantovani, D. (2014). "Covalent grafting of chitosan on plasma-treated polytetrafluoroethylene surfaces for biomedical applications," Journal of Biomaterials and Tissue Engineering 4(11), 915-924. DOI: 10.1166/jbt.2014.1262

Wang, R., Guan, S., Sato, A., Wang, X., Wang, Z., Yang, R., Hsiao, B. S., and Chu, B. (2013). "Nanofibrous microfiltration membranes capable of removing bacteria, viruses and heavy metal ions," Journal of Membrane Science 446, 376-382. DOI: 10.1016/j.memsci.2013.06.020

Wang, Z., Zhang, W., Yu, J., Zhang, L., Liu, L., Zhou, X., Huang, C., and Fan, Y. (2019). "Preparation of nanocellulose/filter paper (NC/FP) composite membranes for high-performance filtration," Cellulose 26, 1183-1194. DOI: 10.1007/s10570-0182121-8

Watson, P., and Bradley, M. (2009). "Canadian pulp fibre morphology: Superiority and considerations for end use potential," The Forestry Chronicle 85(3), 401-408. DOI: $10.5558 / \mathrm{tfc} 85401-3$

Whitaker, S. (1986). "Flow in porous media I: A theoretical derivation of Darcy's law," Transport in Porous Media 1, 3-25. DOI: 10.1007/BF01036523

Yoya, G. K., and Stevanovic, T. (2018). "Organosolv processes: New opportunities for development of high value products from lignins," in: Chemistry of Lignocellulosics: Current Trends, T. Stevanovic (ed.), CRC Press, Boca Raton, FL, USA, pp. 214-230. DOI: $10.1201 / \mathrm{b} 20936$

Zanoaga, M., and Tanasa, F. (2014). "Antimicrobial reagents as functional finishing for textiles intended for biomedical applications. I. Synthetic organic compounds," Chemistry Journal of Moldova 9(1), 14-32. DOI: 10.19261/CJM.2014.09(1).02

Zhang, Q., Li, Q., Young, T. M., Harper, D. P., and Wang, S. (2019a). "A novel method for fabricating an electrospun poly(vinyl alcohol)/cellulose nanocrystals composite nanofibrous filter with low air resistance for high-efficiency filtration of particulate matter," ACS Sustainable Chemistry \& Engineering 7(9), 8706-8714. DOI: 10.1021/acssuschemeng.9b00605

Zhang, S., Kai, C., Liu, B., Zhang, S., Wei, W., Xu, X., and Zhou, Z. (2019b). 'Preparation, characterization and antibacterial properties of cellulose membrane containing N-halamine," Cellulose 26, 5621-5633. DOI: 10.1007/s10570-019-02492-z 
Zhao, M., Liao, L., Xiao, W., Yu, X., Wang, H., Wang, Q., Lin, Y. L., Kilinc-Balci, F. S., Price, A., Chu, L., et al. (2020). "Household materials selection for homemade cloth face coverings and their filtration efficiency enhancement with triboelectric charging," Nano Letters 20(7), 5544-5552. DOI: 10.1021/acs.nanolett.0c02211

Zhong, H., Zhu, Z., Lin, J., Cheung, C. F., Lu, V. L., Yan, F., Chan, C.-Y., and Li, G. (2020). "Reusable and recyclable graphene masks with outstanding superhydrophobic and photothermal performances," ACS Nano 14(5), 6213-6221. DOI: 10.1021/acsnano.0c02250

Zhou, J., Hu, Z., Zabihi, F., Chen, Z., and Zhu, M. (2020). "Progress and perspective of antiviral protective material," Advanced Fiber Materials 2, 123-139. DOI: $10.1007 / \mathrm{s} 42765-020-00047-7$

Article submitted: January 14, 2021; Peer review completed: February 14, 2021; Revised version received and accepted: February 16, 2021; Published: February 25, 2021.

DOI: 10.15376/biores.16.2.Garcia 